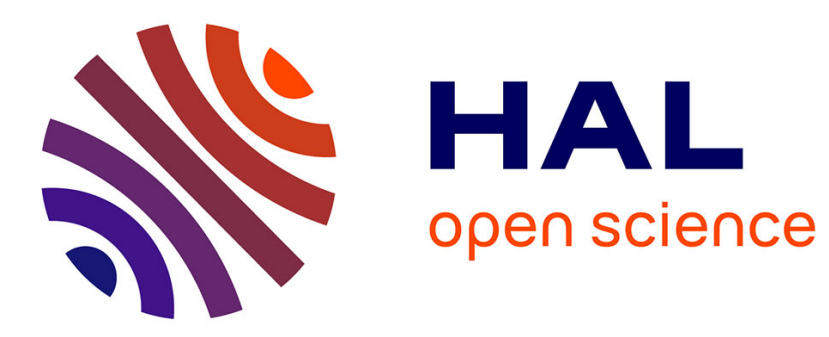

\title{
Irradiation Effects on Polymer-Grafted Gold Nanoparticles for Cancer Therapy
}

\author{
Marine Le Goas, Aurélie Paquirissamy, Dorra Gargouri, Giulia Fadda, \\ Fabienne Testard, C. Aymes-Chodur, Emile Jubeli, Thierry Pourcher, \\ Béatrice Cambien, Serge Palacin, et al.
}

\section{To cite this version:}

Marine Le Goas, Aurélie Paquirissamy, Dorra Gargouri, Giulia Fadda, Fabienne Testard, et al.. Irradiation Effects on Polymer-Grafted Gold Nanoparticles for Cancer Therapy. ACS Applied Bio Materials, 2018, 2, pp.144-154. 10.1021/acsabm.8b00484 . cea-01951373

\section{HAL Id: cea-01951373 https://hal-cea.archives-ouvertes.fr/cea-01951373}

Submitted on 11 Dec 2018

HAL is a multi-disciplinary open access archive for the deposit and dissemination of scientific research documents, whether they are published or not. The documents may come from teaching and research institutions in France or abroad, or from public or private research centers.
L'archive ouverte pluridisciplinaire HAL, est destinée au dépôt et à la diffusion de documents scientifiques de niveau recherche, publiés ou non, émanant des établissements d'enseignement et de recherche français ou étrangers, des laboratoires publics ou privés. 


\section{Irradiation Effects on Polymer-Grafted Gold}

\section{Nanoparticles for Cancer Therapy}

Marine Le Goas, ${ }^{\ddagger}$ Aurélie Paquirissamy, ${ }^{\ddagger}$ Dorra Gargouri, ${ }^{\ddagger}$ Giulia Fadda, ${ }^{\dagger}$ Fabienne

Testard, ${ }^{\ddagger}$ Caroline Aymes-Chodur, ${ }^{\phi}$ Emile Jubeli, ${ }^{\phi}$ Thierry Pourcher, ${ }^{\S}$ Béatrice Cambien, ${ }^{\S}$ Serge Palacin, ${ }^{*}$ Jean-Philippe Renault, ${ }^{*} *$ Geraldine Carrot, ${ }^{*} *$

ॠNIMBE, CEA, CNRS UMR 3685, Université Paris-Saclay, CEA Saclay, 91191 Gif-surYvette Cedex, France.

${ }^{\dagger}$ LLB, CEA, CNRS UMR 12, Université Paris-Saclay, CEA Saclay, 91191 Gif-sur-Yvette Cedex, France.

${ }^{\phi}$ Laboratoire Matériaux et Santé EA 401, Université Paris Sud, UFR de Pharmacie, 5 rue Jean-Baptiste Clément 92296 Châtenay, France.

${ }^{\S}$ Laboratoire TIRO, UMRE 4320, Université de Nice-Sophia Antipolis, CEA, France.

* Corresponding authors: geraldine.carrot@cea.fr jean-philippe.renault@cea.fr 


\section{ABSTRACT}

In the context of cancer treatment, gold nanoparticles (AuNPs) are considered as very promising radiosensitizers. Here, well-defined polymer-grafted AuNPs were synthesized and studied under gamma irradiation to better understand the involved radiosensitizing mechanisms. First, various water-soluble and well-defined thiol-functionalized homopolymers and copolymers were obtained through Atom Transfer Radical Polymerization. They were then used as ligands in the one-step synthesis of AuNPs, resulting in stable hybrid metalpolymer nanoparticles. Second, these nano-objects were irradiated in solution by gamma rays at different doses. Structures were fully characterized through SEC, SAXS and SANS measurements, prior and after irradiation. We were thus able to quantify and to localize radiation impacts onto the grafted polymers, revealing the production sites of reactive species around AuNPs. Both external and near-surface scissions were observed. Interestingly, the ratio between these two effects was found to vary according to the nature of polymer ligands. Medium-range and long-distance dose enhancements could not be identified from the calculated scission yields, but several mechanisms were considered to explain high yields found for near-surface scissions. Then, cytotoxicity was shown to be equivalent for both nonirradiated and irradiated polymer-grafted NPs, suggesting that released polymer fragments were non-toxic. Finally, the potential to add bioactive molecules such as anticancer drugs has been explored by grafting doxorubicin (DOX) onto the polymer corona. This may lead to nano-objects combining both radiosensitization and chemotherapy effects. This work is the first one to study in details the impact of radiation on radiosensitizing nano-objects combining physical, chemical and biological analyses.

KEYWORDS. Polymer-grafted AuNPs, irradiation, radiosensitization, SANS, SAXS, cytotoxicity, doxorubicin. 


\section{INTRODUCTION}

Nanotechnologies are being widely studied for medical applications, both diagnosis and treatment. They have already shown great promise, especially to treat cancer through various strategies such as chemotherapy, ${ }^{1}$ photothermal therapy, ${ }^{2}$ hyperthermia ${ }^{3}$ or radiation therapies. ${ }^{4}$ High-Z elements nanoparticles are of particular interest for the latter, considering their ability to amplify damaging effects of both photon and ion radiations, and gold was among the most investigated elements.

First study on radiosensitization by gold nanoparticles (AuNPs) was done by Hainfield et al., 5 where they showed a significant increase in the one-year survival rate for carcinoma-bearing mice treated with gold nanoparticles prior to X-ray therapy. This in vivo study preceded several other in vitro ones to characterize the radiosensitizing effects of gold. ${ }^{6}$ A large variety of objects has been observed through these studies. For example, nanoparticles (NPs) size has ranged from $1.9 \mathrm{~nm}$ to $74 \mathrm{~nm},{ }^{7-9}$ various NPs shapes have been designed ${ }^{10}$ and NPs surface coating could either be made of small molecules (citrate, ${ }^{8,11}$ thiol, ${ }^{12,13}$ glucose $^{14}$ ), polymers (mainly PEG) $)^{9,15-17}$ or biomolecules. ${ }^{18}$ Used experimental conditions can also be very diverse, particularly the type and energy of the ionizing radiation source, the concentration of nanoparticles, the incubation time, the cell line, etc... A few studies have also focused on the radiosensitizing effects of NPs directly on $\mathrm{DNA}^{7,19,20}$ or proteins. ${ }^{21}$ However, despite numerous studies in the literature, the mechanism behind this radiosensitizing effect remains difficult to study and is not fully understood yet. Many questions still arise: Where does the energy deposit take place? At which stage does this effect occur? Is it related to the radiolysis of water (indirect effect) or to the energy received by gold (direct effect)? Is the effect local or remote? A number of theoretical models have been developed, ${ }^{6,22,23}$ which envision either a proximity physical enhancement effect $^{24}$ due to low-energy secondary electrons, a remote 
physical enhancement effect ${ }^{25,26}$ due to high-energy secondary electrons, a chemical enhancement effect ${ }^{27,28}$ due to surface catalysis, or a biological enhancement effect. ${ }^{29}$ For a better understanding of these effects, we tried to develop an integrated physical, chemical and biological method based on model objects.

To answer these questions, it is essential to have access to stable model nano-objects. In the present study, we chose to use polymer-grafted NPs to evaluate the impact of irradiation via the characterization of the polymer corona. To our knowledge, this is the first time that this type of nano-objects have been used for radiosensitization together with a detailed characterization to evaluate radiation effects. In a forthcoming paper, more detailed biological effects and particularly, in vitro and in vivo studies will be presented. ${ }^{30}$

A covalently grafted polymer corona does not only help to stabilize the nanoparticles (NPs) but it also improves the solubility, the diffusion inside cells, and permits additional effects via the grafting of a therapeutic agent. ${ }^{31}$ Here, we synthesized AuNPs with different polymer corona via a "grafting through" or a "direct" process (polymer-AuNPs). ${ }^{32}$ Controlled radical polymerization (ATRP) was used to design polymer ligands of different nature with controlled molecular weights. Then, these polymer ligands were used directly for the synthesis of polymer-AuNPs. This strategy had several advantages compared to more conventional "grafting from" and "grafting to" methods. First, the prior preparation of polymer ligands allowed a good knowledge of molecular weights/polydispersity of the grafted chains, without the difficulties of a further degrafting reaction, as needed in the "grafting from" route. ${ }^{33-35}$ Second, compared to "grafting to", we considered that the surface chemistry of finally afforded gold NPs was better controlled in the direct method. Indeed, in the case of gold nanoparticles, "grafting to" method usually involves reduction via citrate followed by ligand displacement, ${ }^{36,37}$ thus leading to the presence of both charged molecules and polymer chains onto the surface. ${ }^{38,39}$ In the present study, it was of particular importance to have good 
control and knowledge of the surface state of our nano-objects, as radiation effects were evaluated via polymer fragments analysis. The objective was to use the grafted polymer corona to map, on a nanometric scale, the production sites of reactive species in the vicinity of gold surface under irradiation. Note that these polymer-grafted NPs were particularly stable and solutions may be kept for several months without any formation of aggregates. For the irradiation study, a detailed characterization of the nano-objects was also performed via size exclusion chromatography (SEC), thermogravimetry (TGA), small-angle X-ray scattering (SAXS) and small-angle neutron scattering (SANS). Polymer-grafted NPs were then studied regarding their biocompatibility (cytotoxicity measurements) before and after irradiation, prior to in vitro and in vivo radiosensitizing studies that will be fully described in a forthcoming paper. ${ }^{30}$

Two types of nano-objects were particularly studied: poly(methacrylic acid)-grafted gold nanoparticles (PMAA-AuNPs), and gold nanoparticles coated with poly(hydroxyethyl methacrylate-co-methacrylic acid) (P(HEMA-MAA)-AuNPs), that provided another corona structure, leading to different physico-chemical properties and potential for chemical modification. Indeed, nanoparticles can be inherently multifunctional and strategies combining radiotherapy and chemotherapy have already been proposed. ${ }^{40,41}$ To complete the radiation stability measurements on hybrid nanosystems, we performed the grafting of doxorubicin onto the polymer corona and analyzed the conservation of its biological effectiveness. 


\section{EXPERIMENTAL SECTION}

Materials. Monomers were all distilled prior to use. All other reactants were mainly purchased from Sigma-Aldrich (France) and used as received. L929 mouse fibroblast cell line was purchased from the American Type Culture Collection (ATCC, USA). Dulbecco's Modified Eagle Medium (DMEM), Dulbecco's Phosphate Buffer Saline (DPBS), Trypsin and Gentamicin/Amphotericin B were obtained from Fisher Scientific (France). Fetal Bovine Serum and MTT (3-(4,5-dimethylthiazol-2-yl)-2,5-di-phenyl tetrazolium bromide) were bought from Sigma-Aldrich (France).

Initiator preparation. Bis[2-(2'-bromoisobutyryloxy)ethyl]disulfide was obtained via an esterification between $2,2^{\prime}$-dithioethanol $(\geq 85,0 \%)$ and $\alpha$-bromoisobutyryl bromide $(98 \%)$. This reaction has already been described in the literature. ${ }^{32}$ Briefly, $3.40 \mathrm{~g}$ of $2,2^{\prime}-$ dithioethanol and $4.2 \mathrm{~g}$ of pyridine were dissolved in $30 \mathrm{~mL}$ THF under an argon atmosphere at $0^{\circ} \mathrm{C}$, before the addition of $12.2 \mathrm{~g}$ of $\alpha$-bromoisobutyryl bromide. After 1 hour, the solution was left stirring at ambient temperature for 24 hours. After filtration, the resulting solution was dissolved in chloroform and washed twice with a $2 \mathrm{M} \mathrm{HCl}$ solution. Solvent was then evaporated and a colorless oil was obtained ( $85 \%$ yield).

${ }^{1} \mathrm{H}$ NMR (CDCl3) $\delta(\mathrm{ppm}): 4.44(\mathrm{t}, \mathrm{OCH} 2,4 \mathrm{H}), 2.98(\mathrm{t}, \mathrm{SCH} 2,4 \mathrm{H}), 1.94$ (s, CH3, 12H).

Atom Transfer Radical Polymerization (ATRP). All monomers, ligand ( $\mathrm{N}, \mathrm{N}, \mathrm{N}^{\prime}, \mathrm{N}^{\prime \prime}, \mathrm{N}^{\prime \prime}-$ Pentamethyldiethylenetriamine ; PMDETA), initiator and solvent were degassed prior to the reaction, whereas the whole setup was placed under argon atmosphere. The $\mathrm{Cu}^{\mathrm{I}} \mathrm{Br} / \mathrm{PMDETA} /$ initiator ratio was 2/2/1. After addition of $\mathrm{Cu}^{\mathrm{I}} \mathrm{Br}(99,999 \%)$ and PMDETA $(\geq 98,0 \%)$ in a very small amount of DMF, $20 \mathrm{~mL}$ of monomer (here tert-butyl methacrylate, $t$ BuMA, 98\%, or hydroxyethyl methacrylate, HEMA, 97\% and/or polyethylene glycol methacrylate, PEGMA, average $M_{n}=360 \mathrm{~g} \cdot \mathrm{mol}^{-1}$ ) was added to the solution. Finally, 0.26 
$\mathrm{mL}$ of the initiator was inserted and the reaction started with the increase of temperature to $60^{\circ} \mathrm{C}$. The resulting solution was left to react for 5 hours under inert atmosphere. The polymer was subsequently precipitated in a methanol $(\mathrm{MeOH}) /$ water mixture $(90 / 10)$ and filtrated. Samples were regularly collected during the reaction, in order to determine the conversion rate through gravimetric measurements (see supporting information, S. I.). The afforded polymer ligands were then denominated as poly(tert-butyl methacrylate)-disulfide: PtBuMADS; poly(hydroxyethyl methacrylate)-disulfide: PHEMA-DS; etc.

${ }^{1} \mathrm{H}$ NMR $\left(\mathrm{CDCl}_{3}\right) \delta(\mathrm{ppm})$ : PtBuMA-DS. 1.81-2.06 (m, $\left.\mathrm{CCH}_{2}, 2 \mathrm{H}\right), 1.41\left(\mathrm{~s}, \mathrm{CH}_{3}, 9 \mathrm{H}\right), 1.11-$ 1.02 (m, $\left.\mathrm{CCH}_{3}, 3 \mathrm{H}\right)$; P(HEMA-tBuMA)-DS. 4.10-4.25 (m, $\left.\mathrm{CH}_{2}-\mathrm{OH}, 2 \mathrm{H}\right), 3.75-3.90$ (m, $\mathrm{CH}_{2^{-}}$ $\mathrm{O}, 2 \mathrm{H}), 1.70-2.10\left(\mathrm{~m}, \mathrm{CCH}_{2}, 3 \mathrm{H}\right), 1.30-1.50\left(\mathrm{~m}, \mathrm{CH}_{3}, 8 \mathrm{H}\right), 0.75-1.25\left(\mathrm{~m}, \mathrm{CCH}_{3}, 6 \mathrm{H}\right)$. PHEMA-DS. 4.00-4.20 (m, $\left.\mathrm{CH}_{2}-\mathrm{OH}, 2 \mathrm{H}\right), 3.70-3.90$ (m, $\left.\mathrm{CH}_{2}-\mathrm{O}, 2 \mathrm{H}\right), 1.80-2.20\left(\mathrm{~m}, \mathrm{CH}_{2}\right.$, 2H), 0.80-1.20 (m, $\left.\mathrm{CCH}_{3}, 3 \mathrm{H}\right)$; P(PEGMA-tBuMA)-DS. 3.60-3.75 (m, $\left.\mathrm{CH}_{2}-\mathrm{CH}_{2}-\mathrm{O}, 15 \mathrm{H}\right)$, 3.30-3.40 (m, $\left.\mathrm{CH}_{3}-\mathrm{O}, 3 \mathrm{H}\right), 1.75-2.00\left(\mathrm{~m}, \mathrm{CCH}_{2}, 3 \mathrm{H}\right), 1.40-1.50\left(\mathrm{~m}, \mathrm{CH}_{3}, 8 \mathrm{H}\right), 0.75-1.25$ (m, $\left.\mathrm{CCH}_{3}, 7 \mathrm{H}\right)$; P(PEGMA-HEMA)-DS. 4.00-4.20 (m, $\left.\mathrm{CH}_{2}-\mathrm{OH}, 2 \mathrm{H}\right), 3.75-3.90$ (m, $\left.\mathrm{CH}_{2}-\mathrm{O}, 2 \mathrm{H}\right)$, 3.50-3.75 (m, $\left.\mathrm{CH}_{2}-\mathrm{CH}_{2}-\mathrm{O}, 15 \mathrm{H}\right), 1.60-2.20\left(\mathrm{~m}, \mathrm{CH}_{2}, 5 \mathrm{H}\right), 0.70-1.20$ (m, $\left.\mathrm{CCH}_{3}, 6 \mathrm{H}\right)$.

Hydrolysis of polymer ligands. This procedure was used for all polymers and copolymers containing tert-butyl methacrylate units. ${ }^{34}$ Briefly, $1 \mathrm{~g}$ of PtBuMA-DS or P(HEMA-tBuMA)DS were solubilized in $10 \mathrm{~mL}$ chloroform before the addition of $2.7 \mathrm{~mL}$ of trifluoroacetic acid (TFA). The reaction proceeded until the complete precipitation of poly(methacrylic acid) (PMAA) or P(HEMA-MAA). Efficiency of the hydrolysis reaction was evaluated from thermogravimetry (TGA) and ${ }^{1} \mathrm{H}$ NMR and was $>90 \%$ (see S.I.).

${ }^{1} \mathrm{H}$ NMR (CDCl3) $\delta$ (ppm): PMAA-DS. 1.80-2.20 (m, CCH2, 2H), 1.00-1.20 (m, CCH3, 3H); P(HEMA- MAA)-DS. 4.00-4.10 (m, CH2-OH, 2H), 3.70-3.80 (m, CH2-O, 2H), 1.80-2.20 (m, 
$\mathrm{CCH} 2,3 \mathrm{H}), 0.80-1.25$ (m, CCH3, 6H); P(PEGMA-MAA)-DS. 3.60-3.75 (m, $\mathrm{CH}_{2}-\mathrm{CH}_{2}-\mathrm{O}$, 14H), 3.30-3.40 (m, $\left.\mathrm{CH}_{3}-\mathrm{O}, 3 \mathrm{H}\right), 1.75-2.00\left(\mathrm{~m}, \mathrm{CCH}_{2}, 3 \mathrm{H}\right), 0.75-1.25\left(\mathrm{~m}, \mathrm{CCH}_{3}, 6 \mathrm{H}\right)$.

Synthesis of polymer-grafted gold nanoparticles. $220 \mathrm{mg}$ of $\mathrm{HAuCl}_{4}\left(30 \%_{\mathrm{wt}}\right.$ in dilute $\left.\mathrm{HCl}\right)$ were dissolved in $8 \mathrm{~mL}$ of methanol and mixed with $119 \mathrm{mg}$ of polymer ligands in $8 \mathrm{~mL}$ of methanol. The solution was stirred during 30 minutes before the addition of $75.6 \mathrm{mg}$ of $\mathrm{NaBH}_{4}$ (75.6 mg in $4 \mathrm{~mL}$ of methanol). After 24 hours reaction, the resulting dark red solution was centrifuged to obtain a black precipitate which was subsequently washed in a $\mathrm{MeOH} / \mathrm{ether} \mathrm{mixture} \mathrm{and} \mathrm{dried} \mathrm{under} \mathrm{nitrogen.}$

Characterization routine techniques. ${ }^{1} H$ NMR spectra of disulphide initiator and polymer ligands were obtained from a Bruker AC-400 spectrometer. Organic content ( $\%_{\mathrm{wt}}$ OC) was determined from Thermogravimetric Analysis (TGA) performed on a Mettler-Toledo TGA/DSC at a scan rate of $20{ }^{\circ} \mathrm{C} \min ^{-1}$, up to $800{ }^{\circ} \mathrm{C}$, under oxygen. The associated uncertainty was evaluated to 5\%. Absorption spectra were recorded using a Shimadzu UV2450 double-beam UV-Vis spectrophotometer.

Transmission electron microscopy (TEM). Analyses were carried out on a JEOL-1400 instrument. Samples were prepared by placing $3 \mu \mathrm{L}$ of the $0.33 \mathrm{mg} / \mathrm{mL}$ nanoparticles solution on a carbon-coated copper grid.

Size-exclusion chromatography (SEC). Number average molecular weights $\left(\mathrm{M}_{\mathrm{n}}\right)$, weight average molecular weights $\left(M_{w}\right)$, and polydispersities $\left(M_{w} / M_{n}\right)$ were determined using a GPC 220 system from PolymerLabs (Agilent Technologies) in THF at $35^{\circ} \mathrm{C}$, with a flow rate of 1 $\mathrm{mL} \cdot \mathrm{min}^{-1}$. A series of two $7.5 \mathrm{~mm}$ diameter x $300 \mathrm{~mm}$ Polymer Labs, $5 \mu \mathrm{m}$ particle diameter mixed-E PL gel columns were connected in line to the GPC system. Samples were detected using a refractive index detector. The system was calibrated using poly(ethylene glycol) or 
polystyrene standards (PolymerLabs) in the range of molecular weights 43580-106 g.mol ${ }^{-1}$. The calibration uncertainties were evaluated to be below $4 \%$.

Small-angle neutron scattering (SANS). Experiments were carried out on the PACE spectrometer (Laboratoire Léon Brillouin, Saclay). Three configurations ( $\mathrm{D}=1 \mathrm{~m}, \lambda=4.6 \AA$; $\mathrm{D}=3 \mathrm{~m}, \lambda=4.6 \AA$ and $\mathrm{D}=4.7 \mathrm{~m}, \lambda=13 \AA$ ) enabled to cover a $q$ range of $5 \times 10^{-3} \AA^{-1}-0.3 \AA^{-}$ ${ }^{1}$, which permitted to study objects with dimensions of $\mathrm{R} \sim 1 / \mathrm{q}$, corresponding to sizes from 20 to $0.1 \mathrm{~nm}$. Data treatment was done with a homemade program (PAsiNET, LLB), following standard procedures with $\mathrm{H}_{2} \mathrm{O}$ as the calibration standard. Incoherent background was determined with several H/D mixtures and interpolated for the desired concentrations. Absolute values of the scattered intensity $\left(\mathrm{in}^{-1}\right.$ ) were measured via a determination of the direct beam intensity. Samples were prepared and studied at different concentrations between 5 and $10 \mathrm{mg} / \mathrm{mL}$ in $\mathrm{D}_{2} \mathrm{O}$. SANS also permitted to determine the molecular weight of the scattering object from a concentration study. ${ }^{42}$ Details of the calculation will be given in the results and discussion section.

Small-Angle X-ray Scattering (SAXS). Experiments were carried out on a home-made apparatus equipped with a source based on a Rigaku rotating molybdenum anode $\left(\lambda_{\mathrm{K} \alpha}(\mathrm{Mo})=\right.$ $0.711 \AA$ A) collimated by an Osmic mirror through two hybrid slits $\left(1 \mathrm{x} 1 \mathrm{~mm}^{2}\right)$. Scattering photons were collected on a MAR 345 image plate and a photodiode mounted on the beam stop could monitor the photon flux. Calibration of the sample to detector distance $(72 \mathrm{~cm})$ was obtained with tetradecanol while $3 \mathrm{~mm}$ Lupolen $\left(\mathrm{I}=6 \mathrm{~cm}^{-1}\right)$ and $3 \mathrm{~mm}$ water enabled to normalize detector counts into differential cross section per volume. ${ }^{43}$ Measurements were performed in the $q$ range of 0.03-3.0 $\AA^{-1}$. Samples were measured in $3 \mathrm{~mm}$ Kapton capillaries. Data preanalysis was perfomed using PYSAXS program. ${ }^{44}$ 
Irradiation experiments. Nanoparticles solutions (at 10 and $2.6 \mathrm{mg} / \mathrm{mL}$ for physicochemical and cytotoxicity studies respectively) were irradiated with a GammaCell 3000 Elan irradiator equipped with a ${ }^{137} \mathrm{Cs}$ source emitting $660 \mathrm{keV}$ gamma rays. Before performing analysis of the irradiated residues, dialysis against water (Spectra/Por, molecular weight cutoff of $50 \mathrm{kDa}$ ) was conducted. The mean dose rate of the irradiator was determined to be of $5.5 \mathrm{~Gy} / \mathrm{min}$ by a Fricke dosimetry (uncertainty $5 \%$ ). To prepare the Fricke solution, $22 \mathrm{~mL}$ of $99 \%$ sulfuric acid were diluted in $250 \mathrm{~mL}$ deionized water and mixed with $0.06 \mathrm{~g}$ of $\mathrm{NaCl}$ and $0.392 \mathrm{~g}$ of iron (II) sulfate. Volume was then completed to $1 \mathrm{~L}$ with deionized water and the resulting solution was left away from light for 24 hours prior to any use. After irradiation (doses ranging from 40 to $20000 \mathrm{~Gy}$ ), the $303 \mathrm{~nm}$ absorbance was measured.

Degrafting of polymer chains. $10 \mathrm{mg}$ of irradiated PMAA-AuNPs were precipitated and then solubilized in $100 \mu \mathrm{L}$ of water. $2 \mathrm{~mL}$ of gold etchant $\left(\mathrm{I}_{2} / \mathrm{KI}\right)$ solution was then added and the mixture was stirred overnight. After being centrifuged to remove impurities, the dark solution was dialyzed (Spectra/Por, molecular weight cut-off of $3.5 \mathrm{kDa}$ ) against water. The resulting colorless solution was evaporated and then solubilized in THF to be analyzed by SEC. ${ }^{45}$

Cell culture studies. Mouse fibroblasts (cell line L929), derived from subcutaneous and adipose tissues of a C3H/An male, were cultivated in DMEM supplemented with $10 \%$ fetal bovine serum at $37^{\circ} \mathrm{C}$ in a humidified incubator with $5 \% \mathrm{CO}_{2}$. L929 cells were sub-cultured at $80-90 \%$ confluency. For MTT assays, cells were seeded in 96-well plates at a density of 2500 cells/well. After 24 hours, diluted suspensions $(0.1-500 \mu \mathrm{g} / \mathrm{mL})$ of polymer-AuNPs in DMEM supplemented with $10 \%$ fetal bovine serum, $0.25 \mu \mathrm{g} / \mathrm{mL}$ Amphotericin B and $10 \mu \mathrm{g} / \mathrm{mL}$ Gentamicin were added (only supplemented DMEM was used for controls). Both nonirradiated and irradiated solutions were tested. Incubation with NPs was performed during 48 hours in order to comply with the norm used to assess cytotoxicity for such nanomaterials (NF 
EN ISO 10993-5). After the 48-hour exposure, NPs suspensions were removed and $100 \mu \mathrm{L}$ of clean DMEM were added in each well, followed by $25 \mu \mathrm{L}$ of MTT solution $(5 \mathrm{mg} / \mathrm{mL}$ in PBS) for a 2-hour incubation. Media was then eliminated and $200 \mu \mathrm{L}$ of DMSO were finally added to dissolve the formazan crystals. Absorbance measurements were taken at $570 \mathrm{~nm}$. To assess reproducibility, 6 wells were used for each condition. Cell viability was calculated as the absorbance ratio between cells exposed to our nano-objects and control (untreated) cells.

Grafting of Doxorubicin. $25 \mathrm{mg}$ of PMAA-AuNPs were solubilized in $5 \mathrm{~mL}$ of phosphate buffer (PBS) at $\mathrm{pH}=7.8$. Then, $4.65 \mathrm{mg}$ of 1-ethyl-3-(3-dimethylaminopropyl) carbodiimide hydrochloride (EDC) and $5 \mathrm{mg}$ of N-hydroxysuccinimide (NHS) were added and the reaction proceeded under stirring for $2 \mathrm{~h}$. Finally, $300 \mathrm{mg}$ of doxorubicin (DOX) solution were added, and the mixture was allowed to react for $24 \mathrm{~h}$. Then, purification was performed via dialysis against water (Spectra/Por, molecular weight cut-off of $3.5 \mathrm{kDa}$ ). 


\section{RESULTS AND DISCUSSION}

Polymer-grafted gold nanoparticles. The synthetic strategy used here to prepare polymergrafted nanoparticles was the "grafting through" method, consisting in the preparation of polymer ligands, followed by the direct synthesis of gold nanoparticles (AuNPs) in the presence of these functional polymers. For the present study on radiation effects on nanoobjects, it was essential to have well-defined polymer chains to be able to evaluate this effect through the polymer corona characteristics (molecular weight and gyration radius). Therefore, this "direct" or "grafting through" method was much more adapted here rather than the usual "grafting from" technique that we usually used to form similar nano-objects. ${ }^{33,34}$ It was also much more appropriate than the conventional "grafting to" techniques which usually require AuNPs stabilized with anionic citrate, part of which may be left onto the surface, leading to uncontrolled surface chemistry. ${ }^{38,39}$ and some toxicity. ${ }^{46,47}$ The "grafting through" process also permitted to reach critical small sizes ${ }^{32,48}$ required to enter the cell nucleus. ${ }^{49}$

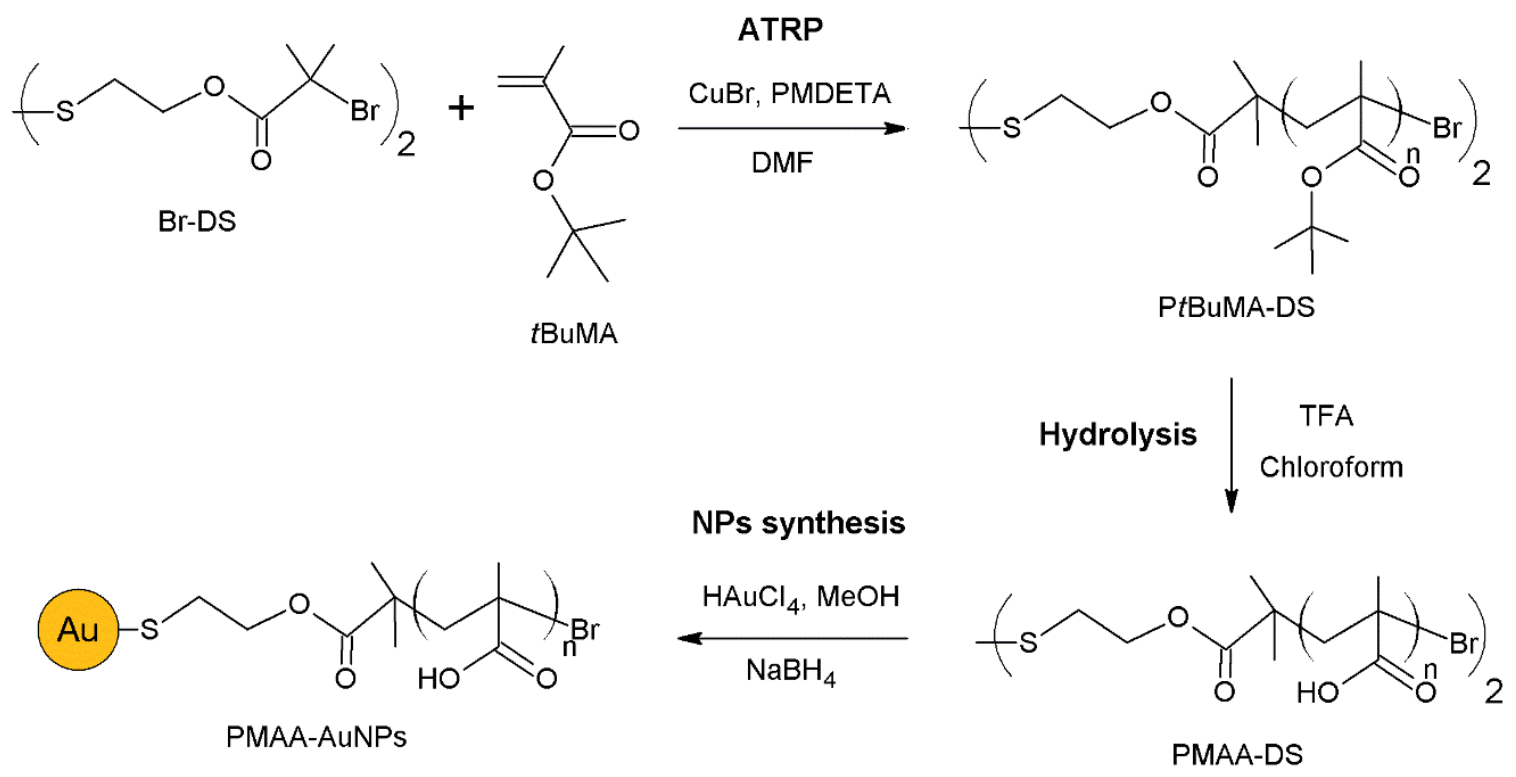

Scheme 1. Synthesis of PMAA-grafted gold nanoparticles (PMAA-AuNPs). 
Polymer ligands were prepared in two steps (see Scheme 1). First, methacrylate polymers were synthesized from a disulfide initiator using Atom Transfer Radical Polymerization (ATRP). Second, hydrolysis was performed to obtain water-soluble polymer chains. A library of different ligands (homopolymers and statistical copolymers) were obtained: PMAA-DS (polymethacrylic acid disulfide), PHEMA-DS (poly(hydroxyethyl methacrylate) disulfide)), P(HEMA-MAA)-DS (Poly(methacrylic acid-co-hydroxyethyl methacrylate disulfide)), P(PEGMA-MAA)-DS (Poly(polyethyleneglycol methacrylate-co-methacrylic acid)), P(PEGMA-HEMA)-DS (Poly(polyethyleneglycol methacrylate-co-hydroxyethyl methacrylate)). All functionalized polymers were characterized through gravimetric measurements (kinetics study), ${ }^{1} \mathrm{H}$ NMR and SEC (size exclusion chromatography). Polymerization kinetics studies (see supporting information, S. I.) gave final polymer conversions between 45 and $70 \%$ after 2 hours reaction, depending on the initial monomer(s). Also, a good control of the polymerization was stated by the linear variation of $\ln \left(\left[\mathrm{M}_{0}\right] /[\mathrm{M}]\right)$ as a function of $\mathrm{t}^{2 / 3}$ (see $\mathrm{S}$. I.).

Table 1. Molecular weight $\left(M_{n}\right)$ and polydispersities $\left(M_{w} / M_{n}\right)$ of polymers disulfide obtained from ATRP, determined from size-exclusion chromatography (SEC); before and after hydrolysis.

\begin{tabular}{|ccccccc|}
\hline Samples & $\begin{array}{c}\% \\
\text { Conversion }\end{array}$ & $\begin{array}{c}\mathbf{M}_{\mathbf{n} \text { Theo }} \\
\left(\mathbf{g . m o l}^{-1}\right)\end{array}$ & $\begin{array}{c}\mathbf{M}_{\mathbf{n} \text { Exp }} \\
\left(\mathbf{g . m o l}^{-1}\right)\end{array}$ & $\mathbf{M}_{\mathbf{w}} / \mathbf{M}_{\mathbf{n}}$ & $\begin{array}{c}\text { Hydrolysis } \\
\text { Rate } \%^{\text {\% }}\end{array}$ & $\begin{array}{c}\mathbf{M}_{\mathbf{n} \text { Exp }} \\
\left(\mathbf{g . m o l}^{-1}\right)\end{array}$ \\
\hline PMAA-DS & 70 & 28000 & 18800 & 1.3 & 98 & 4600 \\
$\begin{array}{c}\text { PHEMA-DS } \\
\text { P(HEMA-MAA)- }\end{array}$ & 58 & 11600 & 6075 & $/$ & $/$ & $/$ \\
$\begin{array}{c}\text { DS } \\
\text { P(PEGMA- }\end{array}$ & 45 & 15000 & 13300 & 1.4 & 93 & 10100 \\
$\begin{array}{c}\text { MAA)-DS } \\
\text { P(PEGMA- }\end{array}$ & $/$ & 10200 & 4500 & 1.8 & 91 & 3700 \\
HEMA)-DS & $/$ & 10600 & 19800 & 1.7 & $/$ & $/$ \\
\hline
\end{tabular}


Molecular weights $\left(\mathrm{M}_{\mathrm{n}}\right)$ obtained from SEC measurements have been reported in Table 1 . Polydispersity values were slightly higher than what we expected from ATRP process $(\geq 1.3)$. This could be due to the use of a difunctional initiator, which might increase the probability of irreversible termination processes. This may also explain the slight divergence between theoretical and measured $\mathrm{M}_{\mathrm{n}}$.

After hydrolysis to PMAA (hydrolysis rates were estimated through ${ }^{1} \mathrm{H}$ NMR measurements to be between 91 and 98\%), molecular weights of polymer ligands were also evaluated. Measured values were much lower than expected (regarding the difference of molar mass between $t$ BuMA and MAA). Indeed, as values were almost half than expected, we concluded that chains had been cleaved via the disulfide bridge during the hydrolysis treatment. Therefore, for the next step, i.e. the synthesis of nanogold, we were rather in the presence of thiol-functional polymers than disulfide ligands (in the case of PMAA-DS only). However, this was not really a problem as the final nano-object structure (gold core and corona) would remain the same. As said, the formation of AuNPs in the presence of disulfide (or thiolfunctional) polymers acting as ligands for the control of gold salt reduction corresponds to a "direct" or "grafting-through" method. Therefore, gold salt was reduced by sodium borohydride and nanoparticles' growth was controlled by the reaction of polymer ligands with gold (gold-sulfur bond), leading to a covalently-bonded corona.

After the synthesis of AuNPs, the presence of polymers was confirmed by ${ }^{1} \mathrm{H}$ NMR (see S. I.). The resulting nano-objects could easily be dispersed in water thanks to the presence of polymer corona. The afforded polymer-grafted AuNPs solutions were particularly stable in water and in all good solvents for polymers or copolymers forming the corona. Suspensions may be kept for months without any aggregation. As said, this was a particular advantage regarding the scope of our study (impact of irradiation onto polymer-grafted AuNPs) and the possible application in medicine (radiosensitizing nano-objects). However, the reverse 
drawback of this was the high difficulty to get completely rid of free polymers using usual techniques (precipitation/centrifugation). Indeed, several tests have been performed to selectively precipitate the grafted AuNPs using solvent mixtures (THF/Ethanol). At the ratio $60 / 40$, it was possible to isolate partially free polymer chains. However, despite numerous efforts, we could not avoid the presence of remaining free polymers which was evidenced by TGA and SANS measurements. Nevertheless, we decided to turn this difficulty into an advantage by using these free polymers as an internal reference to measure impacts of irradiation.

A)

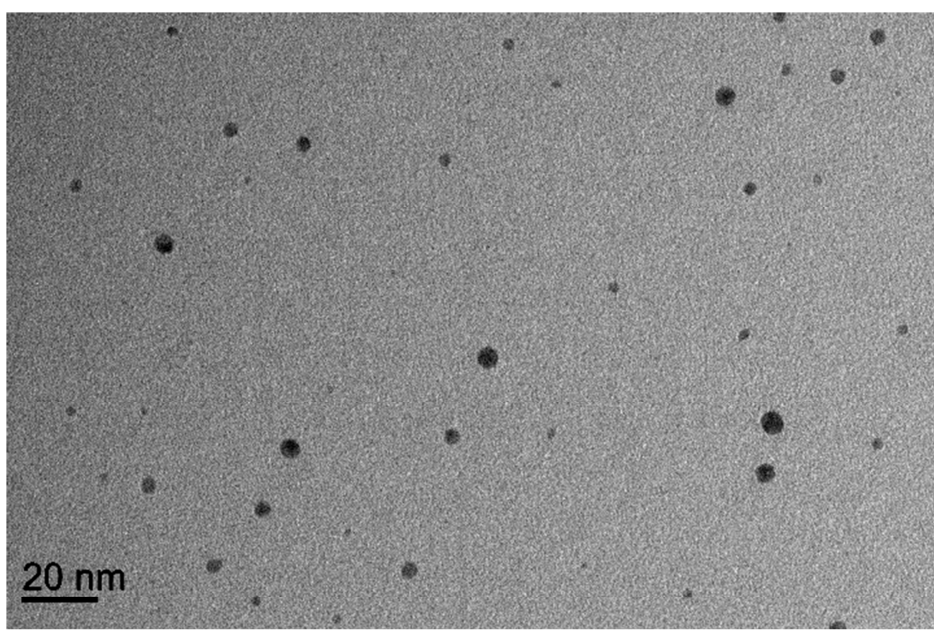

B)

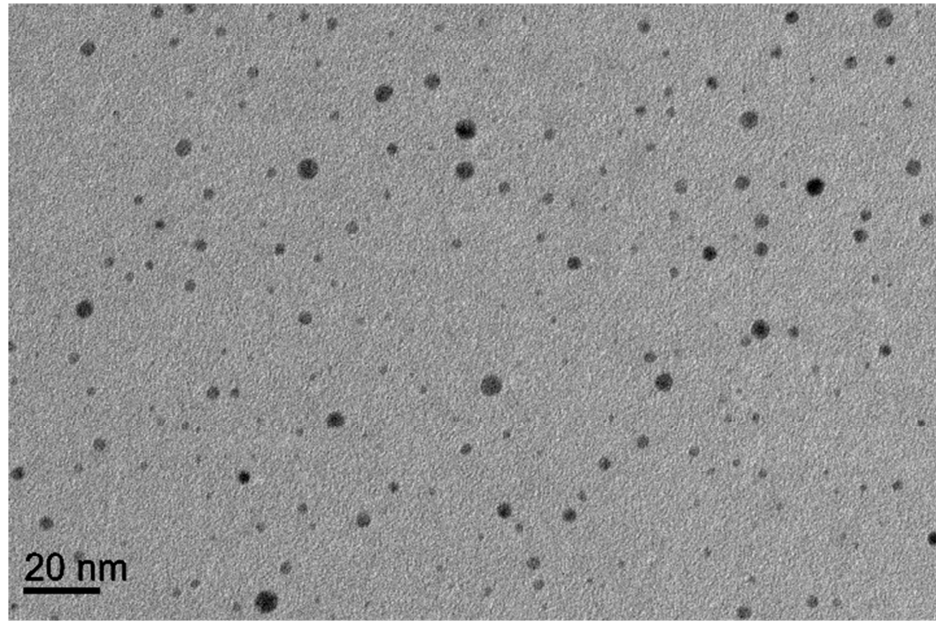

Figure 1. TEM micrograph of (A) PMAA-AuNPs and (B) P(HEMA-MAA)-AuNPs. 
After the synthesis, a detailed characterization of the nano-objects was performed to get welldefined references prior to irradiation. As a first observation, samples were studied with TEM (Figure 1). With TEM, only the gold cores were visible and no aggregation was observed. Both types of nanoparticles (with different polymer corona) were found to have rather monodispersed cores with a spherical morphology. Diameters could be estimated between 3 and $6 \mathrm{~nm}$ and between 4 and $6 \mathrm{~nm}$, for PMAA-AuNPs and P(HEMA-MAA)-AuNPs, respectively (see size diagrams in S. I.). The spherical structure was also confirmed by UV-vis spectroscopy as only one plasmon band was measured: $\lambda_{\text {P(HEMA-MAA)-AuNPs }}=515 \mathrm{~nm}, \lambda_{\text {PMAA- }}$ $\mathrm{AuNPs}=517 \mathrm{~nm}$ and $\lambda_{\mathrm{P}(\mathrm{PEGMA}-\mathrm{MAA})-\mathrm{AuNPs}}=510 \mathrm{~nm}$ (see S. I.). From UV-Vis spectroscopy, it was also possible to estimate NPs sizes which were in the range of values given by SAXS.

For the sake of clarity, the rest of the study was mainly focused onto PMAA-AuNPs and P(HEMA-MAA)-AuNPs. The size of metallic cores was further characterized by SAXS (Figure 2). Only the metallic part scatters X-rays, as the polymer corona does not scatter in water in this q range. ${ }^{50}$ For both samples (PMAA-AuNPs and P(HEMA-MAA)-AuNPs), the Bragg peak of gold could be observed at $2.66 \AA^{-1}$ (see S. I.). Based on TEM observations, a spherical model was used to fit experimental results, giving a radius of $15 \AA$ for PMAAAuNPs (Gaussian distribution, PDI = 0.5), and $21 \AA$ for P(HEMA-MAA)-AuNPs (lognorm distribution, PDI = 0.3) (see S. I. and Figure 2). These results were quite consistent with the values obtained by TEM. Regarding the corona characterization, we first performed thermogravimetric analysis (TGA). Results are shown in S. I. For all samples, TGA curves could be divided in two parts: a slow decrease in $\%_{\mathrm{wt}}$ OC ( $\%_{\mathrm{wt}}$ organic content) was observed, followed by a plateau and a final slope which was measured at $\mathrm{T} \geq 500^{\circ} \mathrm{C}$. The total $\%_{\mathrm{wt}} \mathrm{OC}$ measured were 71 and $73 \%$ for PMAA-AuNPs and P(HEMA-MAA)-AuNPs, respectively. However, we already suspected that this percentage was distorted by the presence of free chains. These results will further be completed by SANS. 

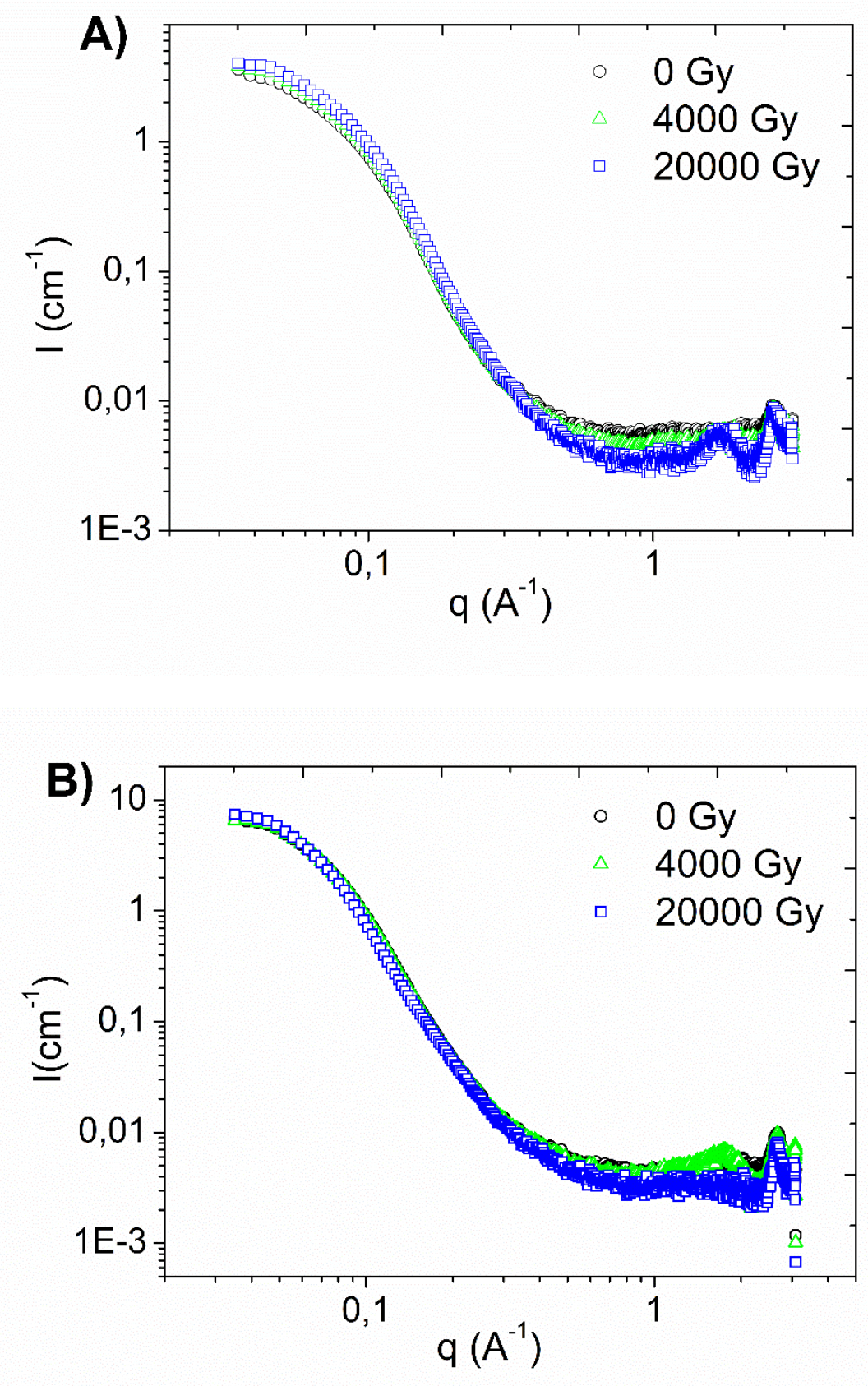

Figure 2. SAXS spectra of polymer-grafted AuNPs $(10 \mathrm{mg} / \mathrm{mL}$ solutions in water) before and after irradiation: (A) PMAA-AuNPs and (B) P(HEMA-MAA)-AuNPs.

SANS analysis was performed to get a detailed characterization of the whole structure of nano-objects (Figure 3). Solutions of polymer-grafted AuNPs (PMAA-AuNPs and P(HEMAMAA)-AuNPs) were prepared at $10 \mathrm{mg} / \mathrm{mL}$ in deuterated water. $\mathrm{D}_{2} \mathrm{O}$ was used to obtain a 
maximum contrast matching with the polymer corona regarding the corresponding neutron scattering length densities $\left(\rho_{\text {PMAA }}=1.10 \times 10^{10} \mathrm{~cm}^{-2} ; \rho_{\text {P }(\text { HEMA-PMAA })}=1.37 \times 10^{10} \mathrm{~cm}^{-2}\right)$.
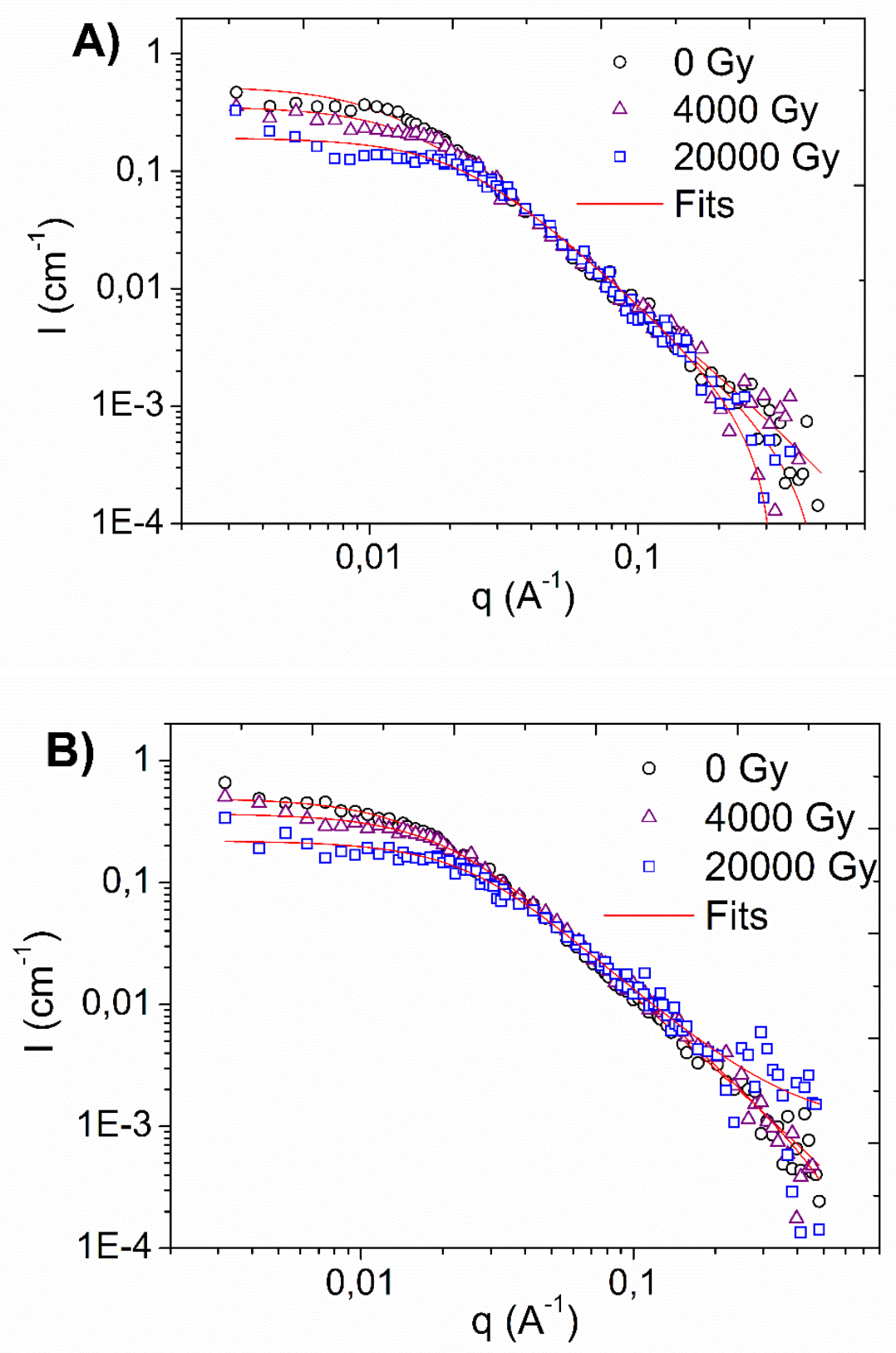

Figure 3. SANS spectra of (A) PMAA-AuNPs and (B) P(HEMA-MAA)-AuNPs, before and after irradiation. 
In these conditions, and considering the small size of the gold core $\left(\rho_{\mathrm{Au}}=4.50 .10^{10} \mathrm{~cm}^{-2}\right)$, the gold signal was found to be negligible, so that only the polymer corona contributed to the signal (Figure 3). In the low $q$ domain, a plateau could be observed, which is typical of nonaggregated objects with finite size. For these $q$ values, the radius of gyration $R_{g}$ could be estimated using Guinier approximation $\left(q R_{g} \leq 1\right)$ :

$$
I(q) \propto \exp \left(-q^{2} \frac{R_{g}^{2}}{3}\right)
$$

By plotting $\ln (I)$ versus $q^{2}$ we could determine $R_{g}$ for each type of ligand (see S. I.). Calculated values were of $102 \pm 2 \AA$ for PMAA-AuNPs, and $84 \pm 1 \AA$ for P(HEMA-MAA)AuNPs.

The decrease in $q^{-2}$ in the intermediate domain indicated that the whole geometry was close to a Gaussian chain. Then, the total signal could be estimated from the Debye model with the following form factor:

$$
\mathrm{P}_{\text {Chaîne }}(q, R g)=\frac{2\left(e^{\left(-\mathrm{q}^{2} \mathrm{Rg}^{2}\right)}-1+\mathrm{q}^{2} \mathrm{Rg}^{2}\right)}{\left(\mathrm{q}^{2} \mathrm{Rg}^{2}\right)^{2}}
$$

SANS plots were fitted using this model (Figure 3). Then, $\mathrm{R}_{\mathrm{g}}$ values calculated from these fits were found to be rather close to the Guinier values $(120 \pm 3 \AA$ for PMAA-AuNPs and $90 \pm 1$ $\AA$ for P(HEMA-MAA)-AuNPs). Therefore, we decided to use this model and the corresponding $\mathrm{R}_{\mathrm{g}}$ values for the further study of irradiation effects onto the polymer corona (Table 2).

SANS also permitted to determine the molecular weight of the polymer corona. ${ }^{42}$ At a given concentration, the scattered intensity extrapolated at $q=0$ was measured. From these values, it was possible to calculate the apparent molecular weight $\left(\mathrm{M}_{\mathrm{app}}\right)$ of the object using the following equation: 


$$
\lim _{c \rightarrow 0}\left(\frac{I_{0}}{c}\right)=K^{2} M\left(1-2 A_{2} c+\cdots\right) \text { with } K^{2}=\left(\frac{b_{1}-b_{0} \frac{v_{1}}{v_{0}}}{m_{1}}\right)
$$

Where $I_{0}$ corresponds to the scattered intensity at $\mathrm{q}=0$ of the polymer corona, $b_{1}$ and $b_{0}$ are respectively, the scattering length densities of the polymer and the solvent, $v_{1}$ and $v_{0}$, their specific volumes, $A_{2}$, the second coefficient of the Viriel equation, and $M$, the molecular weight of the polymer corona.

Table 2. SANS characteristic values of PMAA-AuNPs and P(HEMA-MAA)-AuNPs before and after irradiation.

\begin{tabular}{|ccccc|}
\hline $\begin{array}{c}\text { Nano- } \\
\text { objects }\end{array}$ & Dose $(\mathbf{G y})$ & $\mathbf{I}_{\mathbf{0}}\left(\mathbf{c m}^{\mathbf{- 1}}\right)$ & $\begin{array}{c}\boldsymbol{R}_{\boldsymbol{g}} \text { of nano- } \\
\text { objects }(\mathbf{\AA})\end{array}$ & $\begin{array}{c}\mathbf{M}_{\text {app }} \text { of the corona } \\
(\mathbf{g} / \mathbf{m o l})\end{array}$ \\
\hline PMAA- & $\mathbf{0}$ & $0.53 \pm 0.02$ & $120 \pm 3$ & $21000 \pm 800$ \\
AuNPs & $\mathbf{4 0 0 0}$ & $0.35 \pm 0.01$ & $98 \pm 3$ & $14200 \pm 350$ \\
& $\mathbf{2 0 0 0 0}$ & $0.19 \pm 0.01$ & $69 \pm 2$ & $7500 \pm 400$ \\
\hline P(HEMA- & $\mathbf{0}$ & $0.49 \pm 0.01$ & $90 \pm 1$ & $21900 \pm 450$ \\
MAA)- & $\mathbf{4 0 0 0}$ & $0.37 \pm 0.01$ & $74 \pm 1$ & $16500 \pm 450$ \\
AuNPs & $\mathbf{2 0 0 0 0}$ & $0.22 \pm 0.01$ & $58 \pm 1$ & $9800 \pm 450$ \\
\hline
\end{tabular}

Impact of irradiation. Using both SAXS, SANS and SEC, it was possible to evaluate quantitatively the effects of irradiation onto the polymer corona. Polymer-grafted AuNPs solutions were irradiated using gamma rays (at 4000 and $20000 \mathrm{~Gy}$ ), under $\mathrm{O}_{2}$ (air) atmosphere. As mentioned before, the major constraint in our system was the difficulty to separate free polymer chains from the polymer-grafted AuNPs. SANS characterization permitted to overcome this problem as only the polymer corona contributes to the scattering signal. Indeed, regarding the low molecular weight of the remaining free chains, they would not contribute to the scattering signal in this q range. Therefore, we could directly quantify the 
irradiation effect onto the corona (Table 2). Using the same model as described before and the molecular weight calculation, we could estimate $\mathrm{R}_{\mathrm{g}}$ and $\mathrm{M}_{\mathrm{app}}$, which both showed a clear decrease with irradiation. $\mathrm{R}_{\mathrm{g}}$ was decreasing from 120 to $69 \AA$ (20 kGy) and from 90 to $58 \AA$ for PMAA-AuNPs and P(HEMA-MAA)-AuNPs, respectively. We also noticed a decrease in $\mathrm{M}_{\text {app }}$ from 21000 to $7500 \mathrm{~g} \cdot \mathrm{mol}^{-1}$ for PMAA-AuNPs, and from 21850 to $9800 \mathrm{~g}^{\mathrm{mol}} \mathrm{mor}^{-1}$ for P(HEMA-MAA)-AuNPs.

At the same time, no change was observed in SAXS spectra which characterized the scattering of gold cores (Figure 2). This means that irradiation did not affect the nano-objects' core so that irradiation effects were only visible onto the polymer corona. ${ }^{1} \mathrm{H}$ NMR spectra also showed that there was no change in the chemical groups of the ligands (see S. I.).

To go further in the understanding of irradiation effects onto the polymer corona, we performed SEC analysis on both grafted and free polymer chains. In order to isolate grafted chains, dissolution of the gold core was done using iodine solution (see experimental section). In this particular case, centrifugation and dialysis were used to isolate the grafted chains. As mentioned before, we did not succeed to completely wash our polymer-grafted AuNPs from the residual free polymers. However, after irradiation, several trials with centrifugation from THF permitted to isolate some free chains. Therefore, it was possible to measure both 'free chains' and 'grafted chains' molecular weights via SEC. Results are detailed in Table 3.

Figure 4 shows the chromatograms obtained from isolated grafted chains, before and after irradiation, for both PMAA-AuNPs and P(HEMA-MAA)-AuNPs. It is clear from these that in both cases, SEC peaks were shifted to higher retention times with irradiation. Quantitative results from these measurements have been summarized in Table 3. Note that in the case of P(HEMA-MAA)-AuNPs, only the isolation of grafted chains from NPs was performed successfully (isolation of free chains was more difficult). 

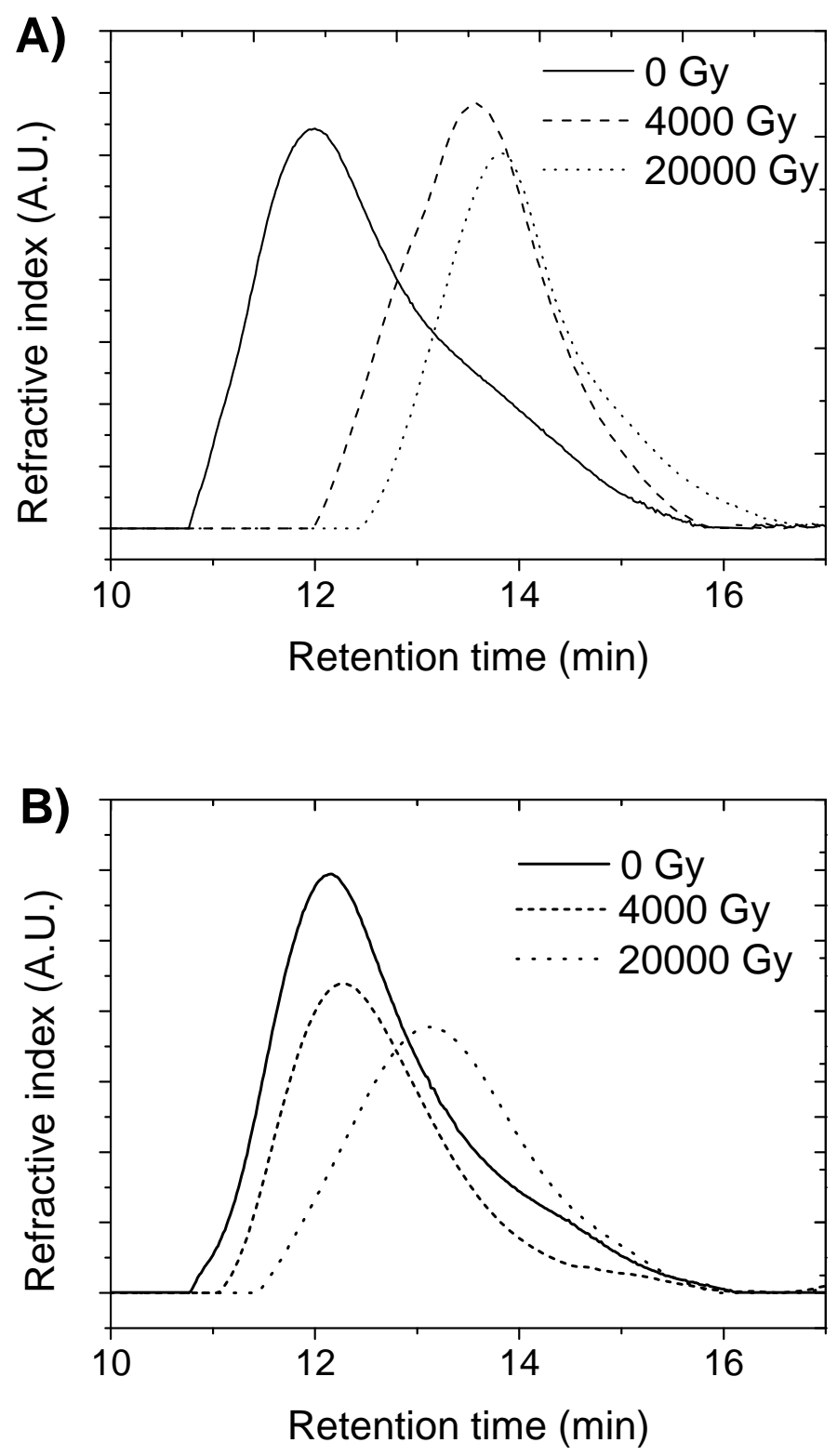

Figure 4. Irradiation effects on PMAA-AuNPs: SEC measurements after irradiation of degrafted polymer chains from (A) PMAA-AuNPs and (B) P(HEMA-MAA)-AuNPs.

From these values and knowing the molecular weight of total polymer corona, it was then possible to estimate a grafting density of polymer chains of $4.6 \pm 0.2$ to $4.4 \pm 0.1$ chains/ AuNP for PMAA-AuNPs and P(HEMA-MAA)-AuNPs, respectively (corresponding to $0.15 \pm$ 0.006 and $0.07 \pm 0.003$ chains $/ \mathrm{nm}^{2}$, Table 3 ). These values were in the range of what was 
expected regarding the very small size of the gold core $\left(\mathrm{R}_{\mathrm{g}}=1.5\right.$ to $\left.2 \mathrm{~nm}\right)$ and slightly lower than what was obtained from "grafting from" routes, ${ }^{33,34}$ probably due to a more important steric hindrance effect.

Table 3. SEC characteristic values of free and grafted chains before and after irradiation.

\begin{tabular}{|c|c|c|c|c|c|c|c|}
\hline $\begin{array}{l}\text { Nano- } \\
\text { objects }\end{array}$ & $\begin{array}{l}\text { Dose } \\
(\mathbf{G y})\end{array}$ & $\begin{array}{c}\text { Free } \\
\text { chains } \mathbf{M}_{\mathbf{n}} \\
\left(\text { g.mol }^{-1}\right)\end{array}$ & $\begin{array}{c}\text { Free } \\
\text { chains } \\
\mathbf{M}_{\mathbf{w}} / \mathbf{M}_{\mathbf{n}}\end{array}$ & $\begin{array}{c}\text { Grafted } \\
\text { chains } \mathbf{M}_{\mathbf{n}} \\
\left(\text { g.mol }^{-1}\right)\end{array}$ & $\begin{array}{c}\text { Grafted } \\
\text { chains } \\
M_{w} / M_{n}\end{array}$ & $\begin{array}{l}\begin{array}{c}\mathbf{d}_{\text {grafting }} \\
\text { (chains/ }\end{array} \\
\text { AuNP) }\end{array}$ & $\begin{array}{c}\mathbf{d}_{\text {grafting }} \\
\text { (chains/ } \\
\left.\mathbf{n m}^{2}\right)\end{array}$ \\
\hline $\begin{array}{l}\text { PMAA- } \\
\text { AuNPs }\end{array}$ & $\begin{array}{c}0 \\
4000 \\
20000\end{array}$ & $\begin{array}{c}3800 \\
2600 \\
1900^{*}\end{array}$ & $\begin{array}{c}1.1 \\
1.3 \\
1.2^{*}\end{array}$ & $\begin{array}{l}4900 \\
2900 \\
2500\end{array}$ & $\begin{array}{l}1.6 \\
1.2 \\
1.1\end{array}$ & $\begin{array}{l}4.6 \pm 0.2 \\
4.9 \pm 0.1 \\
3.0 \pm 0.2\end{array}$ & $\begin{array}{l}0.15 \pm 0.006 \\
0.17 \pm 0.003 \\
0.11 \pm 0.004\end{array}$ \\
\hline $\begin{array}{l}\text { P(HEMA } \\
\text {-MAA)- } \\
\text { AuNPs }\end{array}$ & $\begin{array}{c}0 \\
4000 \\
20000\end{array}$ & $\begin{array}{l}1 \\
1 \\
1\end{array}$ & $\begin{array}{l}1 \\
1 \\
1\end{array}$ & $\begin{array}{l}5500 \\
5600 \\
3100\end{array}$ & $\begin{array}{l}1.4 \\
1.3 \\
1.3\end{array}$ & $\begin{array}{l}4.4 \pm 0.1 \\
2.9 \pm 0.1 \\
3.1 \pm 0.2\end{array}$ & $\begin{array}{l}0.07 \pm 0.003 \\
0.05 \pm 0.003 \\
0.06 \pm 0.003\end{array}$ \\
\hline
\end{tabular}

* Note that high dose data must be discarded, as free polymer has been enriched by chains that were released from the nano-objects by near-surface scissions.

Quantification and localization of the cuts. From results given by SEC and SANS, it was possible to propose a model to explain the degradation of the polymer corona. After being degrafted from AuNPs, polymer chains showed a decrease in molecular weight. A number of scission events $(r)$ could then be obtained using the following equation: ${ }^{51}$

$$
\bar{M}_{n}(i r r)=\frac{\bar{M}_{n}(0)}{1+r}
$$

In order to be exhaustive, we also chose to measure the scission yield for the initial polymer ligand (PMAA-DS, see Scheme 1). The corresponding scission yield (calculated with respect to the dose received by the solution) could be evaluated at $2 \times 10^{-7}$ mol. $\mathrm{J}^{-1}$. Comparatively, the one obtained for PMAA-AuNPs is $1.6 \times 10^{-7}$ mol. $\mathrm{J}^{-1}$ (see all yield values in S. I.). Analysis of free polymer in solution in the presence of AuNPs could be more complex as its contribution 
may be masked by the polymer corona fragments' one. However, it was showed that this latter contribution was minimal at $4000 \mathrm{~Gy}$. Thus, this allowed us to consider the scission yield calculated at this dose. The resulting value of $1.6 \times 10^{-7} \mathrm{~mol} . \mathrm{J}^{-1}$ for free polymer in the presence of AuNPs was comparable to the two others given above. The scission yield obtained for degrafted P(HEMA-MAA) was much lower: $2.7 \times 10^{-8}$ mol. $\mathrm{J}^{-1}$. This is probably due to its longer side chain which could scavenge radicals without leading to scissions.

An original feature for both grafted P(HEMA-MAA) and PMAA was that polydispersity values $\left(\mathrm{M}_{\mathrm{w}} / \mathrm{M}_{\mathrm{n}}\right)$ did not increase with the radiation dose, as expected for random scissions (Table 3). Results obtained for the grafted polymers could be explained by scissions occurring towards chain ends (the so-called percent cuts). ${ }^{52}$ Indeed, the shape of SEC curves was very similar to the one presented in Bose et al. for this type of mechanism. Since the probability of scission is higher for long polymers, they are preferentially attacked compared to smaller ones, thus reducing their size and leading to a decrease of the polydispersity. This therefore suggested an external shaving of the polymer corona (Scheme 2).

In complement to previous measurements (SEC, TGA...), SANS (small angle neutron scattering) was used to quantify the amount of grafted polymers. Indeed, as surface events may lead to some polymer degrafting, we evaluated the total number of chains grafted onto one nanoparticle, using the Debye analysis of SANS data at different doses (Table 3). We could first notice that the decrease in $\mathrm{R}_{\mathrm{g}}$ was in agreement with the molecular weight evolution measured by SEC. This tends to confirm the external shaving process of the corona described previously. We also observed that the total molecular weight $\left(\mathrm{M}_{\mathrm{app}}\right)$ of the polymer corona decreased when the irradiation dose increased (Table 2). Therefore, grafting densities (Table 3) could be calculated from SANS and SEC, and were also found to decrease when the dose increased, confirming that there were scission events occurring near the surface. The Au$\mathrm{S}$ bond was the most probable site but scissions may also occur onto monomer units located in 
the immediate vicinity of the Au surface. Degrafting yields could also be calculated from these data. For PMAA-AuNPs, a $1.1 \times 10^{-8}$ mol. $\mathrm{J}^{-1}$ yield was calculated with respect to the dose received by water. For P(HEMA-MAA)-AuNPs, the value was $4.8 \times 10^{-8}$ mol. $\mathrm{J}^{-1}$. Yields of polymer scissions occurring onto the external corona (Scheme 2) were completely compatible with an effect of radicals produced in solution. Indeed, scissions in PMAA are triggered by hydrogen abstraction radicals $\left(\mathrm{OH} \cdot\right.$ and $\left.\mathrm{H}^{\cdot}\right)$ with a total yield of $3.2 \times 10^{-7}$ mol.J ${ }^{153}$ Apart from their regioselectivity, these external radical effects were not very different in yield compared to the ones occurring in solution. Therefore, we cannot identify long distance $(\mu \mathrm{m})$ and/or medium range $(5-10 \mathrm{~nm})$ dose enhancements in our system. This absence of dose enhancement was not really surprising since the stopping power of AuNPs regarding both gamma rays and Compton electrons is close to the one of water, in the considered energy range. $^{54}$

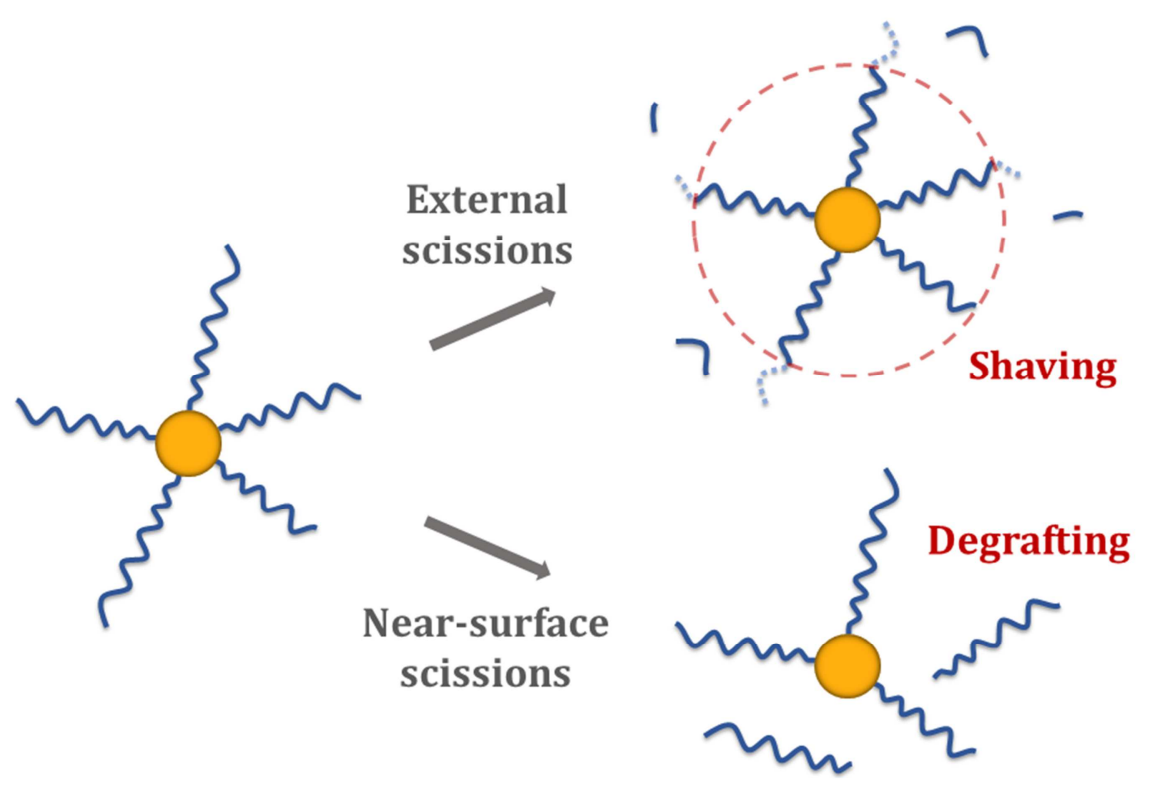

Scheme 2. Impact of external and near-surface scissions on polymer-grafted AuNPs. 
Analysis of the origin of near-surface scissions was obviously more complex. A direct effect of irradiation onto AuNPs cannot be ruled out. The effective scission yield calculated with respect to the amount of energy directly received by nano-objects, would be 10 per $100 \mathrm{eV}$ for PMAA-AuNPs and 50 for P(HEMA-MAA)-AuNPs (see S. I.). This yield is far too high for a classical radical production through water ionization (the total yield in radicals is roughly $6 / 100 \mathrm{eV},{ }^{53}$ even with a two times dose enhancement through Auger electrons). ${ }^{55}$ Therefore this may be compatible with the low-energy electron production through plasmon excitation mechanism invoked on the gold surface, which produces 10 times more reactive species per unit volume. ${ }^{56,57}$ Indeed, mild reductive processes could lead to thiol desorption by Au-S bond disruption (-1 eV required), ${ }^{58}$ and hot electrons near gold surface were proved to be efficient enough for such reduction processes. ${ }^{59}$ Hot electrons in the $\mathrm{eV}$ range have also been shown to be able to fragment polymethacrylate type of backbone. ${ }^{60}$

However, polymer desorption from gold surface could also occur by oxidation in stringent conditions. ${ }^{61}$ Therefore, we cannot completely exclude a surface catalytic effect, similar to the one leading to oxidation of coumarin derivatives. ${ }^{27,28}$ This surface catalysis is an indirect effect, not completely elucidated, where radiolytic species $\left(\mathrm{H}_{2} \mathrm{O}_{2}\right.$ or superoxide) produced in water are activated on gold surface. However, this hypothesis is limited by the fact that polymer degrafting was not observed in our system using $\mathrm{H}_{2} \mathrm{O}_{2}$ alone, and required prior dissolution of the gold core. Either triggered by hot electron or surface catalysis, an interesting point in the degrafting process was its higher efficiency for P(HEMA-MAA) compared to PMAA (whereas external scissions, mainly triggered by HO radicals, were less efficient in P(HEMA-MAA)). Therefore, degrafting is probably not mediated by a hydrogen abstraction mechanism, due for example to $\mathrm{HO} / \mathrm{H}$ surface production, but by a more exotic reactive species. It can also imply that the copolymer structure is more favorable for the action of this species, and probably to the radiosensitizing action of AuNPs. 
Cytotoxicity. In order to complete this physical and chemical description by a first biological insight, we ensured that neither the initial objects nor the polymer fragments released under irradiation would induce toxicity. To evaluate cell viability, MTT assay was performed on murine fibroblasts with both non-irradiated and 400 Gy-irradiated PMAA-AuNPs and P(HEMA-MAA)-AuNPs solutions for a large range of concentrations (Figure 5). Compared to the previous physico-chemical study, we shifted from high doses (4000 Gy) to an intermediate one (400 Gy) which covers all therapeutic ranges.

Non-irradiated PMAA-AuNPs showed some toxicity for NPs concentrations higher than 100 $\mu \mathrm{g} / \mathrm{mL}$, whereas for P(HEMA-MAA)-AuNPs, the toxicity threshold was found to be 500 $\mu \mathrm{g} / \mathrm{mL}$. The difference of toxicity between the two nano-objects shows the impact of surface properties on NP-cell interactions. This feature is the object of the in vitro and in vivo studies that will be showed in a forthcoming paper. ${ }^{30}$ Overall, the assessed toxicity should be tempered by the conditions used here. Indeed, the incubation time (48 hours) was longer than the average time used elsewhere (see experimental section). ${ }^{62}$

Solutions irradiated at 400 Gy showed no additional toxicity for both types of nano-objects. These results demonstrated that irradiated samples were not harmful, and that no other longlived toxic species were created under irradiation. In the context of medical use, this property would be highly beneficial as it implies that our nano-objects can be used for their radiosensitizing properties without any risk of inherent toxicity. To complete this study, we also showed via SANS that our nano-objects remained stable in solution (meaning that no size decrease of the polymer corona has been observed) for irradiation below 400 Gy (see SANS spectra in S. I.), i.e. in the range of doses used classically in radiotherapy. We could therefore consider the possibility of incorporating drug molecules onto the polymer corona. 

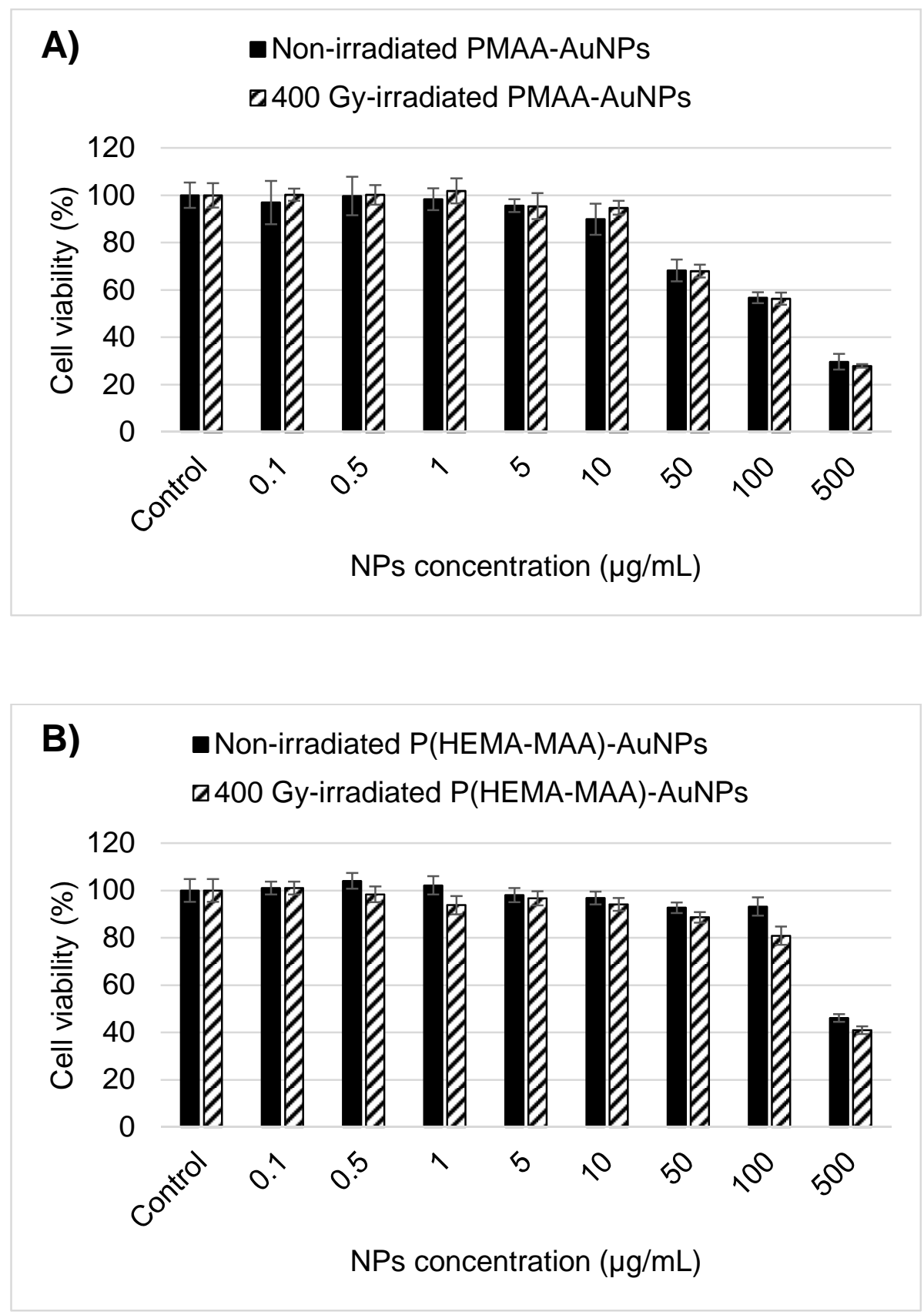

Figure 5. Cytotoxicity of non-irradiated and irradiated (A) PMAA-AuNPs and (B) P(HEMAMAA)-AuNPs solutions.

Grafting of a chemotherapy drug. One interesting improvement of those systems relied on the possibility to graft biologically active molecules such as anticancer drugs. ${ }^{40,41}$ The most 
commonly used is doxorubicin (DOX). To perform grafting onto grafted polymer chains, we took advantage of amine groups and used the standard technique based on intermediate activated esters. We created succinimide groups along the chain from the reaction of PMAA's carboxylic acid groups with EDC and NHS (see experimental section for details). The resulting intermediate activated ester groups then reacted efficiently with the amino groups of DOX. To estimate the amount of grafted DOX, we performed UV spectroscopy (see S. I.) using the absorption peak of doxorubicin at $234 \mathrm{~nm}$. A calibration curve was established for a fixed concentration of PMAA-AuNPs. It was therefore possible to calculate the quantity of grafted DOX, giving a result of one DOX molecule per polymer chain.

To verify that the grafted DOX was still active, we conducted again MTT assays onto these new functional nano-objects (Figure 6). They were compared to free DOX mixed with PMAA-AuNPs. Grafted DOX was found to be toxic for NPs concentrations higher than 5 $\mu \mathrm{g} / \mathrm{mL}$, i.e. equivalent DOX concentrations higher than $0.5 \mu \mathrm{g} / \mathrm{mL}(0.17 \mu \mathrm{M})$. Compared to free DOX, no significant difference in toxicity was found, showing that the grafting procedure kept the drug active. 400 Gy-irradiated solutions of DOX-PMAA-AuNPs and free DOX combined with PMAA-AuNPs were also tested regarding cytotoxicity (Figure 6). For both samples, irradiated NPs showed very small additional toxicity at intermediate concentrations. This could be explained by a toxicity of the degradation species produced when DOX is irradiated $^{63}$ higher than the one of DOX itself. However, considering the very low concentrations of these degradation species ${ }^{63}$ and the minor additional toxic effect observed at $400 \mathrm{~Gy}$, no significant impact should be observed for smaller therapeutic doses. Also, no protection or amplification of irradiation onto the drug was observed for grafted DOX compared to free DOX. Overall, these results showed that toxicity of grafted DOX was maintained even after irradiation. 

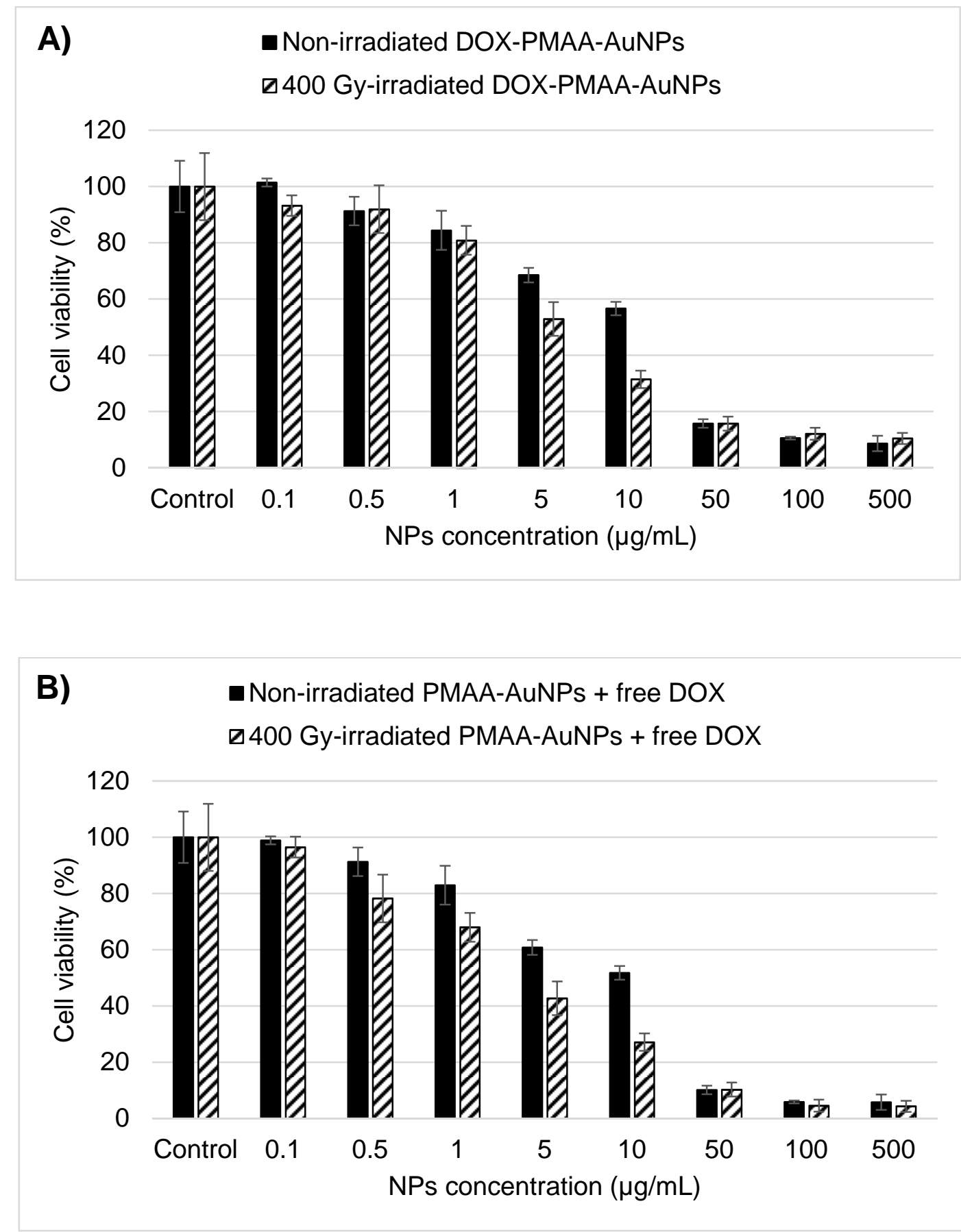

Figure 6. Cytotoxicity of non-irradiated and irradiated (A) DOX-PMAA-AuNPs and (B) PMAA-AuNPs + free DOX solutions. 


\section{CONCLUSION}

A detailed study has been presented here on irradiation effects onto polymer-grafted nanoparticles. Such a study has never been performed before, even though metal NPs are widely investigated for radiotherapy applications. Well-defined polymer-grafted AuNPs were particularly interesting as they led to very stable nano-objects in solution. Also, direct characterization of surface effects induced by irradiation could be performed via the polymer corona. Particularly, scattering techniques (SAXS and SANS), together with SEC measurements and scission yield calculations, showed how nano-objects had been impacted by irradiation. Polymer corona analysis permitted to localize the active sites and the comparison with free polymers showed that no long-range effects were involved. Also, variation of the polymer nature highlighted the presence of short-range effects, either caused by the production of hot electrons or by surface catalysis. The methodology developed here could be applied to other types of hybrid nano-objects. Indeed, it is of particular importance to verify the stability of nano-objects under irradiation in the scope of bio-application. Regarding our objective of designing nano-objects for radiosensitization, we confirmed that they were stable under low dose and that they remained nontoxic after irradiation. As mentioned before, a detailed study of the radiosensitizing properties of these nano-objects will be described in a forthcoming paper. ${ }^{30}$ Finally, we also performed the grafting of a model chemotherapy drug onto the polymer corona, thus showing the possibility to combine chemotherapy and radiotherapy. 


\section{ASSOCIATED CONTENT}

Supporting Information. Polymerization kinetics, ${ }^{1} \mathrm{H}$ NMR spectroscopy and TEM of polymer-grafted PtNPs, UV-Vis spectroscopy of the aqueous solutions, complementary SAXS, SANS and SEC data, TGA, as well as calibration curves for the evaluation of the DOX content, are all described in the supporting information.

\section{AUTHOR INFORMATION}

\section{Corresponding Author.}

*E-mail: geraldine.carrot@ @ cea.fr; jean-philippe.renault@cea.fr. Tel: +33 (0)169084147

ORCID

Geraldine CARROT: 0000-0003-1912-4882

Funding Sources. This work was funded by a public grant overseen by the French National Research Agency (ANR) as part of the "Investissements d'Avenir" program (Labex NanoSaclay, reference: ANR-10-LABX-0035). It was also funded partially by the programme transversal toxicologie of CEA.

Disclosure. All authors declare that no conflict of interest exists.

\section{ACKNOWLEDGEMENT}

We thank Dr. José Teixeira (LLB, CEA-CNRS, UMR 12) for his helpful reading of the manuscript. The platform and expertise of the Electron Microscopy Facility of I2BC (Université Paris Sud, CEA-CNRS UMR 9198) is also acknowledged. 


\section{REFERENCES}

(1) Parhi, P.; Mohanty, C.; Sahoo, S. K. Nanotechnology-Based Combinational Drug Delivery: An Emerging Approach for Cancer Therapy. Drug Discov. Today 2012, 17 (17), 1044-1052.

(2) Calixto, G. M. F.; Bernegossi, J.; de Freitas, L. M.; Fontana, C. R.; Chorilli, M. Nanotechnology-Based Drug Delivery Systems for Photodynamic Therapy of Cancer: A Review. Molecules 2016, 21 (3), 342.

(3) Beik, J.; Abed, Z.; Ghoreishi, F. S.; Hosseini-Nami, S.; Mehrzadi, S.; Shakeri-Zadeh, A.; Kamrava, S. K. Nanotechnology in Hyperthermia Cancer Therapy: From Fundamental Principles to Advanced Applications. J. Controlled Release 2016, 235, 205-221.

(4) Kuncic, Z.; Lacombe, S. Nanoparticle Radio-Enhancement: Principles, Progress and Application to Cancer Treatment. Phys. Med. Biol. 2018, 63 (2), 02 TR01.

(5) Hainfeld, J. F.; Slatkin, D. N.; Smilowitz, H. M. The Use of Gold Nanoparticles to Enhance Radiotherapy in Mice. Phys. Med. Biol. 2004, 49 (18), N309.

(6) Rosa, S.; Connolly, C.; Schettino, G.; Butterworth, K. T.; Prise, K. M. Biological Mechanisms of Gold Nanoparticle Radiosensitization. Cancer Nanotechnol. 2017, 8 (1), 2 .

(7) Brun, E.; Sanche, L.; Sicard-Roselli, C. Parameters Governing Gold Nanoparticle XRay Radiosensitization of DNA in Solution. Colloids Surf. B Biointerfaces 2009, 72 (1), 128-134.

(8) Chithrani, D. B.; Jelveh, S.; Jalali, F.; van Prooijen, M.; Allen, C.; Bristow, R. G.; Hill, R. P.; Jaffray, D. A. Gold Nanoparticles as Radiation Sensitizers in Cancer Therapy. Radiat. Res. 2010, 173 (6), 719-728. 
(9) Zhang, X.-D.; Wu, D.; Shen, X.; Chen, J.; Sun, Y.-M.; Liu, P.-X.; Liang, X.-J. SizeDependent Radiosensitization of PEG-Coated Gold Nanoparticles for Cancer Radiation Therapy. Biomaterials 2012, 33 (27), 6408-6419.

(10) Ma, N.; Wu, F.-G.; Zhang, X.; Jiang, Y.-W.; Jia, H.-R.; Wang, H.-Y.; Li, Y.-H.; Liu, P.; Gu, N.; Chen, Z. Shape-Dependent Radiosensitization Effect of Gold Nanostructures in Cancer Radiotherapy: Comparison of Gold Nanoparticles, Nanospikes, and Nanorods. ACS Appl. Mater. Interfaces 2017, 9 (15), 13037-13048.

(11) McMahon, S. J.; Hyland, W. B.; Brun, E.; Butterworth, K. T.; Coulter, J. A.; Douki, T.; Hirst, D. G.; Jain, S.; Kavanagh, A. P.; Krpetic, Z.; Mendenhall, M. H.; Muir, M. F.; Prise, K. M.; Requardt, H.; Sanche, L.; Schettino, G.; Currell, F. J.; Sicard-Roselli, C. Energy Dependence of Gold Nanoparticle Radiosensitization in Plasmid DNA. J. Phys. Chem. C 2011, 115 (41), 20160-20167.

(12) Geng, F.; Song, K.; Xing, J. Z.; Yuan, C.; Yan, S.; Yang, Q.; Chen, J.; Kong, B. ThioGlucose Bound Gold Nanoparticles Enhance Radio-Cytotoxic Targeting of Ovarian Cancer. Nanotechnology 2011, 22 (28), 285101.

(13) Butterworth, K. T.; Nicol, J. R.; Ghita, M.; Rosa, S.; Chaudhary, P.; McGarry, C. K.; McCarthy, H. O.; Jimenez-Sanchez, G.; Bazzi, R.; Roux, S.; Tillement, O.; Coulter, J. A.; Prise, K. M. Preclinical Evaluation of Gold-DTDTPA Nanoparticles as Theranostic Agents in Prostate Cancer Radiotherapy. Nanomed. 2016, 11 (16), 2035-2047.

(14) Kaur, H.; Pujari, G.; Semwal, M. K.; Sarma, A.; Avasthi, D. K. In Vitro Studies on Radiosensitization Effect of Glucose Capped Gold Nanoparticles in Photon and Ion Irradiation of HeLa Cells. Nucl. Instrum. Methods Phys. Res. Sect. B Beam Interact. Mater. At. 2013, 301, 7-11.

(15) Joh, D. Y.; Sun, L.; Stangl, M.; Al Zaki, A.; Murty, S.; Santoiemma, P. P.; Davis, J. J.; Baumann, B. C.; Alonso-Basanta, M.; Bhang, D.; Kao, G. D.; Tsourkas, A.; Dorsey, J. 
F. Selective Targeting of Brain Tumors with Gold Nanoparticle-Induced Radiosensitization. PLOS ONE 2013, 8 (4), e62425.

(16) Setua, S.; Ouberai, M.; Piccirillo, S. G.; Watts, C.; Welland, M. Cisplatin-Tethered Gold Nanospheres for Multimodal Chemo-Radiotherapy of Glioblastoma. Nanoscale 2014, 6 (18), 10865-10873.

(17) Zhang, P.; Qiao, Y.; Wang, C.; Ma, L.; Su, M. Enhanced Radiation Therapy with Internalized Polyelectrolyte Modified Nanoparticles. Nanoscale 2014, 6 (17), 1009510099.

(18) Chattopadhyay, N.; Cai, Z.; Kwon, Y. L.; Lechtman, E.; Pignol, J.-P.; Reilly, R. M. Molecularly Targeted Gold Nanoparticles Enhance the Radiation Response of Breast Cancer Cells and Tumor Xenografts to X-Radiation. Breast Cancer Res. Treat. 2013, $137(1), 81-91$.

(19) Butterworth, K. T.; Wyer, J. A.; Brennan-Fournet, M.; Latimer, C. J.; Shah, M. B.; Currell, F. J.; Hirst, D. G. Variation of Strand Break Yield for Plasmid DNA Irradiated with High-Z Metal Nanoparticles. Radiat. Res. 2008, 170 (3), 381-387.

(20) Xiao, F.; Zheng, Y.; Cloutier, P.; He, Y.; Hunting, D.; Sanche, L. On the Role of LowEnergy Electrons in the Radiosensitization of DNA by Gold Nanoparticles. Nanotechnology 2011, 22 (46), 465101.

(21) Brun, E.; Duchambon, P.; Blouquit, Y.; Keller, G.; Sanche, L.; Sicard-Roselli, C. Gold Nanoparticles Enhance the X-Ray-Induced Degradation of Human Centrin 2 Protein. Radiat. Phys. Chem. 2009, 78 (3), 177-183.

(22) T. Butterworth, K.; J. McMahon, S.; J. Currell, F.; M. Prise, K. Physical Basis and Biological Mechanisms of Gold Nanoparticle Radiosensitization. Nanoscale 2012, 4 (16), 4830-4838. 
(23) Her, S.; Jaffray, D. A.; Allen, C. Gold Nanoparticles for Applications in Cancer Radiotherapy: Mechanisms and Recent Advancements. Adv. Drug Deliv. Rev. 2017, 109 (Supplement C), 84-101.

(24) Lee, C.; Cheng, N. N.; Davidson, R. A.; Guo, T. Geometry Enhancement of Nanoscale Energy Deposition by X-Rays. J. Phys. Chem. C 2012, 116 (20), 11292-11297.

(25) Davidson, R. A.; Guo, T. Average Physical Enhancement by Nanomaterials under XRay Irradiation. J. Phys. Chem. C 2014, 118 (51), 30221-30228.

(26) Chang, J.; Taylor, R. D.; Davidson, R. A.; Sharmah, A.; Guo, T. Electron Paramagnetic Resonance Spectroscopy Investigation of Radical Production by Gold Nanoparticles in Aqueous Solutions Under X-Ray Irradiation. J. Phys. Chem. A 2016, 120 (18), 28152823.

(27) Cheng, N. N.; Starkewolf, Z.; Davidson, R. A.; Sharmah, A.; Lee, C.; Lien, J.; Guo, T. Chemical Enhancement by Nanomaterials under X-Ray Irradiation. J. Am. Chem. Soc. 2012, 134 (4), 1950-1953.

(28) Sicard-Roselli, C.; Brun, E.; Gilles, M.; Baldacchino, G.; Kelsey, C.; McQuaid, H.; Polin, C.; Wardlow, N.; Currell, F. A New Mechanism for Hydroxyl Radical Production in Irradiated Nanoparticle Solutions. Small 2014, 10 (16), 3338-3346.

(29) Taggart, L. E.; McMahon, S. J.; Currell, F. J.; Prise, K. M.; Butterworth, K. T. The Role of Mitochondrial Function in Gold Nanoparticle Mediated Radiosensitisation. Cancer Nanotechnol. 2014, 5, 5.

(30) Le Goas, M.; Paquet, M.; Paquirissamy, A.; Guglielmi, J.; Compin, C.; Thariat, J.; Vassaux, G.; Geertsen, V.; Renault, J.-P.; Carrot, G.; Pourcher, T.; Cambien, B. Improving ${ }^{131}$ I Radioiodine Therapy by Hybrid Polymer-Grafted Gold Nanoparticles. Submitted. 
(31) Muddineti, O. S.; Ghosh, B.; Biswas, S. Current Trends in Using Polymer Coated Gold Nanoparticles for Cancer Therapy. Int. J. Pharm. 2015, 484 (1-2), 252-267.

(32) Bach, L. G.; Islam, M. R.; Jeong, Y. T.; Gal, Y. S.; Lim, K. T. Synthesis and Characterization of Chemically Anchored Adenosine with PHEMA Grafted Gold Nanoparticles. Appl. Surf. Sci. 2012, 258 (7), 2816-2822.

(33) Carrot, G.; Gal, F.; Cremona, C.; Vinas, J.; Perez, H. Polymer-Grafted-Platinum Nanoparticles: From Three-Dimensional Small-Angle Neutron Scattering Study to Tunable Two-Dimensional Array Formation. Langmuir 2009, 25 (1), 471-478.

(34) Gal, F.; Perez, H.; Noel, V.; Carrot, G. Water-Soluble Polymer-Grafted Platinum Nanoparticles for the Subsequent Binding of Enzymes. Synthesis and SANS. J. Polym. Sci. Part Polym. Chem. 2012, 50 (2), 289-296.

(35) Drockenmuller, E.; Colinet, I.; Damiron, D.; Gal, F.; Perez, H.; Carrot, G. Efficient Approaches for the Surface Modification of Platinum Nanoparticles via Click Chemistry. Macromolecules 2010, 43 (22), 9371-9375.

(36) Zhao, P.; Li, N.; Astruc, D. State of the Art in Gold Nanoparticle Synthesis. Coord. Chem. Rev. 2013, 257 (3), 638-665.

(37) Yilmaz, G.; Demir, B.; Timur, S.; Becer, C. R. Poly(Methacrylic Acid)-Coated Gold Nanoparticles: Functional Platforms for Theranostic Applications. Biomacromolecules 2016, 17 (9), 2901-2911.

(38) Park, J.-W.; Shumaker-Parry, J. S. Strong Resistance of Citrate Anions on Metal Nanoparticles to Desorption under Thiol Functionalization. ACS Nano 2015, 9 (2), 1665-1682.

(39) Dinkel, R.; Braunschweig, B.; Peukert, W. Fast and Slow Ligand Exchange at the Surface of Colloidal Gold Nanoparticles. J. Phys. Chem. C 2016, 120 (3), 1673-1682. 
(40) Zhou, H.; Zhang, Y.; Su, G.; Zhai, S.; Yan, B. Enhanced Cancer Cell Killing by a Targeting Gold Nanoconstruct with Doxorubicin Payload under X-Ray Irradiation. RSC Adv. 2013, 3 (44), 21596-21603.

(41) Cui, T.; Liang, J.-J.; Chen, H.; Geng, D.-D.; Jiao, L.; Yang, J.-Y.; Qian, H.; Zhang, C.; Ding, Y. Performance of Doxorubicin-Conjugated Gold Nanoparticles: Regulation of Drug Location. ACS Appl. Mater. Interfaces 2017, 9 (10), 8569-8580.

(42) Higgins, J. S.; Benoit, H. C. Polymers and Neutron Scattering; Oxford Science Publications; Clarendon Press, 1996.

(43) Zemb, T.; Taché, O.; Né, F.; Spalla, O. Improving Sensitivity of a Small Angle X-Ray Scattering Camera with Pinhole Collimation Using Separated Optical Elements. Rev. Sci. Instrum. 2003, 74 (4), 2456-2462.

(44) Taché, O.; Rouzière, S.; Joly, P.; Amara, M.; Fleury, B.; Thill, A.; Launois, P.; Spalla, O.; Abécassis, B. MOMAC: A SAXS/WAXS Laboratory Instrument Dedicated to Nanomaterials. J. Appl. Crystallogr. 2016, 49 (5), 1624-1631.

(45) Ohno, K.; Koh, K.; Tsujii, Y.; Fukuda, T. Synthesis of Gold Nanoparticles Coated with Well-Defined, High-Density Polymer Brushes by Surface-Initiated Living Radical Polymerization. Macromolecules 2002, 35 (24), 8989-8993.

(46) Uboldi, C.; Bonacchi, D.; Lorenzi, G.; Hermanns, M. I.; Pohl, C.; Baldi, G.; Unger, R. E.; Kirkpatrick, C. J. Gold Nanoparticles Induce Cytotoxicity in the Alveolar Type-II Cell Lines A549 and NCIH441. Part. Fibre Toxicol. 2009, 6, 18.

(47) Freese, C.; Uboldi, C.; Gibson, M. I.; Unger, R. E.; Weksler, B. B.; Romero, I. A.; Couraud, P.-O.; Kirkpatrick, C. J. Uptake and Cytotoxicity of Citrate-Coated Gold Nanospheres: Comparative Studies on Human Endothelial and Epithelial Cells. Part. Fibre Toxicol. 2012, 9, 23. 
(48) Wang, Z.; Tan, B.; Hussain, I.; Schaeffer, N.; Wyatt, M. F.; Brust, M.; Cooper, A. I. Design of Polymeric Stabilizers for Size-Controlled Synthesis of Monodisperse Gold Nanoparticles in Water. Langmuir 2007, 23 (2), 885-895.

(49) Huo, S.; Jin, S.; Ma, X.; Xue, X.; Yang, K.; Kumar, A.; Wang, P. C.; Zhang, J.; Hu, Z.; Liang, X.-J. Ultrasmall Gold Nanoparticles as Carriers for Nucleus-Based Gene Therapy Due to Size-Dependent Nuclear Entry. ACS Nano 2014, 8 (6), 5852-5862.

(50) Genix, A.-C.; Oberdisse, J. Structure and Dynamics of Polymer Nanocomposites Studied by X-Ray and Neutron Scattering Techniques. Curr. Opin. Colloid Interface Sci. 2015, 20 (4), 293-303.

(51) McDonald, C.; Jellinek, H. H. G. A Continuous Light Scattering Technique for Polymer Photolysis. J. Colloid Interface Sci. 1972, 38 (1), 101-108.

(52) Bose, S. M.; Git, Y. Mathematical Modelling and Computer Simulation of Linear Polymer Degradation: Simple Scissions. Macromol. Theory Simul. 2004, 13 (5), 453473.

(53) Tabata, Y. Handbook Radiation Chemistry; CRC-Press, 1990.

(54) NIST. Estar - Stopping power and range tables for electrons https://physics.nist.gov/PhysRefData/Star/Text/ESTAR.html (accessed Feb 5, 2018).

(55) Wälzlein, C.; Scifoni, E.; Krämer, M.; Durante, M. Simulations of Dose Enhancement for Heavy Atom Nanoparticles Irradiated by Protons. Phys. Med. Biol. 2014, 59 (6), 1441.

(56) Verkhovtsev, A. V.; Korol, A. V.; Solov'yov, A. V. Electron Production by Sensitizing Gold Nanoparticles Irradiated by Fast Ions. J. Phys. Chem. C 2014, 119 (20), 11000 11013. 
(57) Verkhovtsev, A. V.; Korol, A. V.; Solov'yov, A. V. Revealing the Mechanism of the Low-Energy Electron Yield Enhancement from Sensitizing Nanoparticles. Phys. Rev. Lett. 2015, 114 (6), 063401.

(58) Azzaroni, O.; Vela, M. E.; Andreasen, G.; Carro, P.; Salvarezza, R. C. Electrodesorption Potentials of Self-Assembled Alkanethiolate Monolayers on $\mathrm{Ag}(111)$ and $\mathrm{Au}(111)$. An Electrochemical, Scanning Tunneling Microscopy and Density Functional Theory Study. J. Phys. Chem. B 2002, 106 (47), 12267-12273.

(59) Cortés, E.; Xie, W.; Cambiasso, J.; Jermyn, A. S.; Sundararaman, R.; Narang, P.; Schlücker, S.; Maier, S. A. Plasmonic Hot Electron Transport Drives Nano-Localized Chemistry. Nat. Commun. 2017, 8, 1-10.

(60) Hobbs, R. G.; Putnam, W. P.; Fallahi, A.; Yang, Y.; Kärtner, F. X.; Berggren, K. K. Mapping Photoemission and Hot-Electron Emission from Plasmonic Nanoantennas. Nano Lett. 2017, 17 (10), 6069-6076.

(61) Wong, E. H. J.; May, G. L.; Wilde, C. P. Oxidative Desorption of Thiols as a Route to Controlled Formation of Binary Self Assembled Monolayer Surfaces. Electrochimica Acta 2013, 109, 67-74.

(62) Khlebtsov, N.; Dykman, L. Biodistribution and Toxicity of Engineered Gold Nanoparticles: A Review of in Vitro and in Vivo Studies. Chem. Soc. Rev. 2011, 40 (3), 1647-1671.

(63) Varshney, L.; Dodke, P. B. Radiation Effect Studies on Anticancer Drugs, Cyclophosphamide and Doxorubicin for Radiation Sterilization. Radiat. Phys. Chem. 2004, 71 (6), 1103-1111. 
Table of Content/Abstract Graphic (TOC).

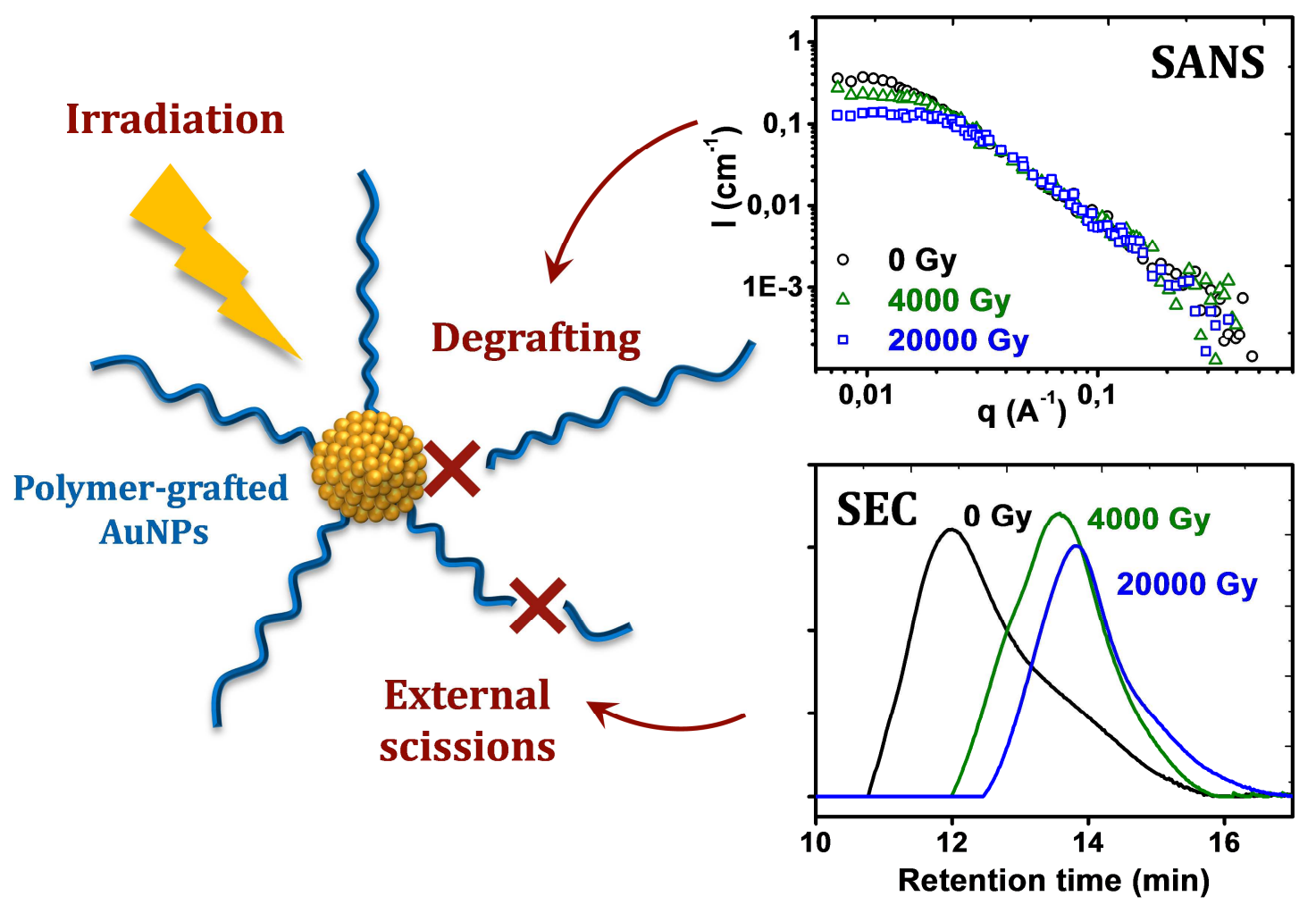

